\title{
Predictions in soil engineering
}

\author{
T. W. LAMBE*
}

This Lecture emphasizes and illustrates the importance of predictions to the practice of civil engineering. Predictions are examined and classified, and comparisons are made between predicted performance and measured performance for eight constructed facilities.

Although there are many techniques for predicting internal stresses, deformations and stability for a geotechnical facility, the application of these techniques has limitations. The major limitations are the difficulty of determining fully and accurately the field situation and the mechanisms which will occur, and the selection of soil parameters to use with prediction methods. The greatest need appears to be for devices and techniques to determine, in situ and continuously with depth, fundamental subsoil properties, such as stress, strength and stress-strain modulus.
Cette communication insiste sur l'importance des prévisions dans la pratique du Génie Civil, et donne des exemples de cette importance. On examine et on classifie divers types de prévision. On compare les comportements prévus aux comportements observés lors de la construction de huit installations. Bicn qu'il $y$ ait de nombreuses techniques de prévision des contraintes, des déformations et de la stabilité d'une installation géotechnique, il y a des limites à l'utilisation de ces techniques. Les principales limitations sont: difficulté de déterminer complètement et exactement les conditions en place et les mécanismes des phénomènes qui surviendront, et de sélectionner les paramètres du sol nécessaires à la mise en œuvre de ces méthodes de prévision. La plus grande nécessité à l'heure actuelle semble être dans la conception de méthodes et de techniques de détermination des propriétés fondamentales du sous-sol, par exemple: contrainte, résistance, module contrainte-déformation, en place, et leurs variations continues avec la profondeur.

\section{INTRODUCTION}

Being selected to give the Rankine Lecture is one of the highest honours given in the international community of geotechnical engineering. I hope that my Lecture will attain the high standards set by the preceding Rankine lecturers. As I am not superstitious, I have no special concern about being the thirteenth Lecturer.

My Lecture focuses on predictions-especially predictions of the performance of civil engineering facilities. A prediction is a forecast; typically, a prediction is obtained by manipulating data according to some method.

Predicting constitutes an integral component-the very heart-of the practice of civil engineering. The successful engineer must not only predict but must also make decisions and take actions on the basis of his predictions. For example, the engineer must identify predictions which are critical to the safety, function, and economics of the project at hand, estimate the reliability of each of his predictions, employ predictions in design and construction, assess the consequences of predictions, especially erroneous predictions, and he must select and execute appropriate actions based on comparisons of the actual situations as they unfold and his predictions. These engineering tasks require considerable judgement.

This Rankine Lecture concentrates on predictions and does not attempt to give complete treatment of the engineering uses of predictions. In particular, the five engineering tasks noted are outside the scope of this Lecture. My Rankine Lecture is based on a review of field projects with which I have been involved since 1950. The original purposes of this review

\footnotetext{
* Edmund K. Turner Professor of Civil Engineering, Massachusetts Institute of Technology.
} 
were to compare predicted performance with measured performance, to attempt to explain discrepancies between predicted and measured performances and to attempt to evaluate various prediction techniques, indicating limitations and reliabilities.

My initial plans were to consider some two dozen cases, dividing them into four groups: foundation loadings, supported excavations, slope stability and earth dams. Only foundation loadings are dealt with. They illustrate conclusions drawn in this Lecture. Not all the details of each case are presented as not all are required to illustrate the points being made.

\section{IMPORTANCE OF PREDICTIONS}

Predictions have always played a significant role in nearly every aspect of man's life. Man apparently feels that if he can predict events correctly he can act in his own best interests, and possibly even alter the events he has predicted, i.e. control his future. This attitude is specially prevalent in the USA where society has always been fluid.

The development of the computer has greatly increased prediction capabilities by permitting enormous quantities of data to be handled. Dynamic modelling has been used to make predictions all the way from narrow scope forecasts in technical fields to forecasts of major world catastrophes. Jay Forrester of the Massachusetts Institute of Technology, (MIT), has for example forecast world starvation and the depletion of natural resources.

The following paragraphs note some of the aspects of life where predictions are of consequence.

\section{History}

History abounds with events where predictions play important roles. Columbus, Galileo and others are famous for their correct predictions. History also records many incorrect predictions, e.g. Columbus would sail to the end of the world and disappear, and anyone travelling at a speed as great as $30 \mathrm{mile} / \mathrm{h}$ would die of suffocation. In a fascinating essay Clarke (1971) discusses famous predictions.

\section{Religion}

Predictions and predicting have played a key role in the development of religion. In many primitive civilizations men wished to find means of learning the unknown. The early Hebrews cast lots and listened to men who claimed to have special information. In declaring God's will, the Prophets of Israel often said that good or evil would result from obeying or disobeying God's will. Thus a predictive element came to be embodied in what they said. If the predicted good or evil came to pass, those who remembered were impressed.

As time went on prophecies became more and more important to religion. Jewish sects identified prophets from the Old Testament as they noted references to later events. The Christians did the same. The Gospel of Matthew mentions events for which it finds precedents in the words of the Old Testament. A reading of the Book of Matthew, noting especially the many references to the Old Testament, indicates the importance which predicting and predictions have had on religion.

\section{Politics}

Predictions of the results of coming elections greatly influence the tactics of the candidates. Political predictions are based on polls in which the voting intentions of a sample of people are extrapolated to predict the actual voting of the entire group of voters. In view of the many shortcomings of polls, one can only be impressed at the relatively high percentage of accurate 
predictions made by pollsters. As the number of people typically interviewed is infinitesimal compared with the number of eligible voters (a typical poll in the 1972 US presidential election extrapolated the voting intentions of between one and two thousand people to indicate the way in which more than 70 million people would vote), it is essential to interview a representative sample.

Polls had great prominence and influence in the 1972 US presidential election. The pollsters' predictions were exceedingly accurate: Gallup predicted that Nixon would get $61 \%$ of the popular vote, Harris predicted $59 \%$, and Nixon actually received $60.7 \%$.

Even though election predictions by pollsters have proved to be generally accurate, there are examples of horrendous predictions. In the 1948 US presidential election, the pollsters predicted certain victory for Republican candidate Thomas E. Dewey. Confident of winning, Dewey campaigned coolly and cautiously-and lost to Harry Truman. So convincing were the pollsters that newspapers appearing the day following the 1948 election actually proclaimed that Dewey had beaten Truman.

\section{Military}

The leader of a military unit in warfare must continuously predict the actions of his enemy as victory or defeat may well be determined by the accuracy of his predictions.

\section{Economics}

Economics seems to consist increasingly of predicting. Economists try to predict accurately the gross national product, the cost of living, the level of unemployment, department store sales, etc. Further, they predict the consequences of governmental policy on these events. Many a common man tries to predict the gyrations of the stock market.

\section{Sports}

Managers and players try to make accurate predictions of the strategies and plays of opposing teams. Spectators and even non-spectators try to predict correctly the outcomes of sporting events-especially horse races. Gamblers place odds on many of the leading sporting events.

\section{Weather}

The weatherman is frequently called a 'weather forecaster' as his major role is to predict. Weather forecasts influence nearly everybody in ways ranging from the trivial ('Shall I carry my umbrella today?') all the way to influencing major decisions ('Should I design and insure my facility against a hurricane?').

\section{Agriculture}

The farmer is continuously forced to make predictions. He bases his decision on whether or not to cut hay on a prediction of weather; he is guided in his planting and animal feeding by his predictions of market conditions, and so on.

\section{CIVIL ENGINEERING PREDICTIONS}

Predicting is a key step in the process of creating and maintaining a constructed facility, i.e. the practice of civil engineering. This section notes and illustrates some of the various types of predictions made by the civil engineer. 


\section{Hydrology}

The design of a water-retention structure, a harbour structure, an offshore structure, etc. depends upon predictions of the nature, magnitude and frequency of storms or floods. The hydrologist normally expresses his predictions in the form of probability.

The hydrologist uses several methods to predict the time and magnitude of a flood. The oldest and simplest method is to extrapolate historical data on stream flow. Increasingly, the hydrologist is working with rainfall data rather than stream flow. Having developed a model for the prediction of stream flow, he then validates his model, i.e. checks it against known situations.

\section{Traffic}

In designing a traffic facility, the engineer selects a design life and then predicts the level of traffic which will occur at a selected time in the future. In 1945, for example, in designing the Boston Central Artery, an expressway extending across the city of Boston, engineers predicted the number of vehicles that would be entering the artery in 1970. In 1970, Godfrey of MIT measured the number of vehicles entering the Central Artery. Fig. 1 compares the 1970 traffic as predicted in 1945 with that actually measured in 1970. Each data point is the number of vehicles entering at a particular location. As can be seen, the engineers' predictions grossly underestimated the traffic.

In making their predictions, the engineers measured traffic, related traffic to population and extrapolated their findings. Many factors combined to sabotage the accuracy of the predictions. The population of Greater Boston (Boston plus 22 surrounding communities) did not increase by $10 \%$ as predicted but only by $\frac{1}{2} \%$. This factor was more than offset by the unexpected increase in affluence of the population which resulted in more cars per family, people moving to the suburbs, etc. Another important reason for the overloading of the Central Artery is that the artery and the entire Boston traffic plan were not carried out as originally envisaged.

\section{Construction costs}

An essential task in any construction project is the prediction of the total construction cost. The engineer working for the owner must predict cost to enable the owner to decide whether or not to proceed with the project as conceived, or to alter it, or to abandon it. The contractor must predict costs in order to submit a bid for the job.

In recent years inflation, labour problems and so on have complicated the already difficult job of correctly predicting construction costs. As an illustration of extreme cases of bad predictions, the examples given in Table 1 may be considered. Table 2 (Drew, 1970) compares predicted and actual costs for nine dam projects. A note from Engineering News Record (1972) indicates that Great Britain also has trouble with poor predictions of construction cost:

Inflation is causing British builders to revise drastically cost estimates for some of the country's biggest construction projects. The Humber Bridge, whose 4,625-ft main suspension span will be the world's longest, is estimated at $\$ 62.4$ million, up from $\$ 35$ million. A new London subway extension, estimated at $\$ 84$ million, has jumped to $\$ 127$ million, with almost $\$ 25$ million of the increase blamed on inflation. A 2,000-mw oil-fired electric power station, in Kent, has gone from $\$ 288$ million to $\$ 480$ million. 
Fig. 1. Predicted and measured numbers of vehicles entering Boston Central Artery at various locations in 1970. Predictions made in 1945

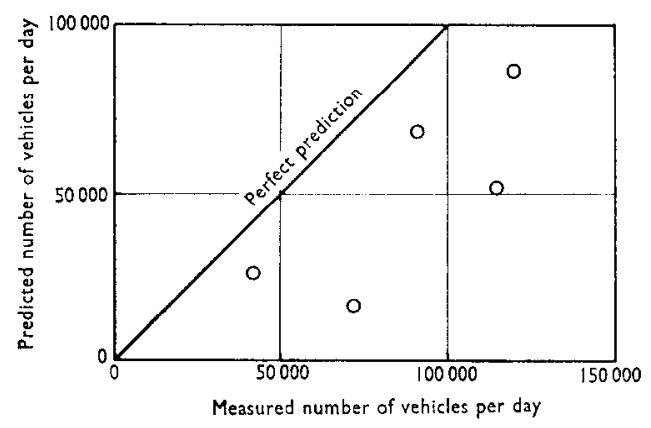

The civil engineer is not the only engineer who has difficulty in accurately predicting construction cost. Consider, for example, the F-111 fighter-bomber. The original predicted cost per aeroplane was $\$ 2924000$. The predicted cost rose to $\$ 6260000$ before the aeroplane was in production (US News and World Report, 1970).

\section{Environment}

Large civil engineering facilities, such as dams, power stations, harbours, highways and pipelines, can significantly influence the physical and human environment over a wide area. Some of the consequences of such large projects are beneficial and some are detrimental. Increasingly, society demands that the environmental consequences of a proposed project be predicted and included among the factors considered when deciding whether or not the project is justified. An 'environmental impact study' is a prediction of the environmental consequences of a project.

Experiences with large dams illustrate the serious and complex environmental consequences that can result from a civil engineering project. Non-technical publications such as Fortune (McQuade, 1970) and Atlantic Monthly (Sterling, 1972) as well as technical publications like Civil

Table 1

\begin{tabular}{l|c|c}
\hline \multicolumn{1}{c|}{ Project } & Predicted cost & Actual cost \\
\hline $\begin{array}{l}\text { Huddinge Hospital, Sweden } \\
\text { South Mall, Albany, New York }\end{array}$ & $\begin{array}{l}\$ 140 \text { million } \\
\$ 380 \text { million }\end{array}$ & $\begin{array}{r}\$ 250 \text { million plus } \\
\$ 1000 \text { million plus }\end{array}$ \\
\hline
\end{tabular}

Table 2. Cost increases on Corps projects (Drew, 1970)

\begin{tabular}{l|r|r|r}
\hline \multicolumn{1}{c|}{ Name of dam } & $\begin{array}{c}\text { Cost estimate at } \\
\text { time project was } \\
\text { authorized, } \$\end{array}$ & $\begin{array}{r}\text { Amount spent } \\
\text { through fiscal } \\
\text { year 1966, \$ }\end{array}$ & $\begin{array}{c}\text { Percentage } \\
\text { Overrun }\end{array}$ \\
\hline Whitney, Texas & 8350000 & 41000000 & 391 \\
John H. Kerr, North Carolina and Virginia & 30900000 & 87733000 & 185 \\
Blakely Mountain, Arkansas & 11080000 & 31500000 & 184 \\
Oahe Reservoir, North and South Dakota & 72800000 & 334000000 & 359 \\
Jim Woodruff, Florida & 24139000 & 46400000 & 92 \\
Chief Joseph, Washington & 104050000 & 144734000 & 39 \\
Fort Peck, Montana & 86000000 & 156859000 & 82 \\
Clark Hill, Georgia and South Carolina & 28000000 & 79695000 & 185 \\
Bull Shoal, Arkansas & 40000000 & 88824000 & 122 \\
\hline
\end{tabular}


Engineering of the American Society of Civil Engineers (Turner, 1971) discuss the tremendous direct and indirect consequences of a large dam. The Aswan Dam offers a good example. One doubts that the planners of this dam made a thorough environmental impact study prior to construction. Even before the dam was completed there was considerable controversy as to the seriousness of the environmental impact of the project. Some (e.g. Sterling, 1972) suggest that the environmental consequences are so detrimental that the entire Aswan Project is not justified. Others (e.g. Wisely, 1972) take the opposite view. A novel by Michael Heim (1972) paints a fascinating and frightening picture of the widespread effects of an overtopping of the Aswan Dam.

The Profession has very limited evaluated experience in making predictions of the environmental and human consequences of civil engineering facilities. We need, and can expect, an increasing effort by civil engineers in the development and evaluation of techniques for predicting environmental and human conscquences of civil enginecring projects. We shall sec more activities like that sponsored by the United Nations educational, scientific and cultural organizations' working group on seismic phenomena associated with large reservoirs.

\section{Geotechnical predictions}

In addition to participating in predictions of construction costs, environmental impact and so on, the geotechnical engineer predicts many aspects of performance of civil engineering facilities. Geotechnical engineering is especially damned and blessed by the importance of predictions and the difficulty of making accurate predictions. Soil and rock, products of natural processes, are highly variable and display very complex behaviour. The range in properties can be tremendous. Permeability can range from less than $10^{-10} \mathrm{~cm} / \mathrm{s}$ for a very plastic, compact clay to more than $10 \mathrm{~cm} / \mathrm{s}$ for very loose, granular soil. Strength can range from zero for a very weak, remoulded plastic clay to more than $10000 \mathrm{lb} / \mathrm{in}^{2}$ for a sound, intact rock and so on. Soil properties can change with time, moisture and stress.

Some of the aspects of performance which the engineer may be required to predict are deformations (both magnitude and rate), stability, and loads, both lateral and vertical, applied to structures resting on or within soil (e.g. struts, sheeting, pipes, tunnels). In addition the engineer may also be required to make predictions of rate of water flow through soil, extent of soil heaving upon freezing and so on.

The soil engineer may be the master predictor. He must work with incomplete, widely scattering and varying data; he frequently has the opportunity to compare his prediction with the predicted event; and he must usually take responsibility for his prediction. He thus develops engineering judgement and does not become obsolete. Further, the approaches to problems and judgement obtained with experience tend to stand the soil engineer well if he moves into other areas, such as the environmental field.

\section{ANATOMY OF PREDICTIONS}

This section examines the anatomy of predictions. Even though the discussion applies to predictions in general, it concentrates on predictions in soil engineering.

A prediction is a forecast of some event yet to take place. It thus implies the future. The engineer, for example, may forecast the magnitude of deformation which a structure will have undergone at a specific date in the future. The engineer might also predict the nature of an existing, but unseen situation. For example, he might predict the nature of soils existing under a structure, i.e. forecast what subsoils would be encountered were an excavation made to expose the unseen soils. 
Figure 2 indicates the predictive process in soil engineering. The soil engineer is usually forced to work with insufficient and inaccurate information as he attempts to determine and delineate the actual situation. Variability in soil properties in both vertical and horizontal directions and the wide range in soil properties greatly complicate the engineer's task. Having cstablished the actual field situation, the engineer then simplifies it, i.e. replaces it with a model. At this stage in the predictive process, the engineer must determine the mechanism(s) which will be involved in the coming event. For example, he might conclude that for a particular foundation loading the subsoil will undergo one-dimensional strain and pore water will escape by one-dimensional flow. The engineer must determine the mechanism involved in order to select an appropriate predictive method and appropriate means of measuring soil parameters.

A very simple and commonly used method of predicting is extrapolating. Plotting data against time, the engineer can continue his plot into the future to obtain a forecast. Linear extrapolation is widely employed. The soil engineer often uses logarithmic scales for his plots, as at least these scales hide some of the scatter of data.

The various predictive methods require soil parameters such as strength, compressibility, permeability and stress-strain modulus. Laboratory tests or in situ tests or a combination of the two can be used to obtain values for soil parameters. Semi-empirical relationships between index characteristics and soil parameters are also used to obtain soil parameters.

The great variability of soil characteristics typically encountered by the engineer leads one to think that the principles of probability theory could be most helpful. In certain aspects of soil engineering, such as earthquake engineering, this expectation has proved to be true. In general, however, probability theory has not yet had a significant influence on the practice of soil engineering.

Manipulating the parameters with the selected method to obtain a prediction usually presents few difficulties, especially now that computers, mini-computers and mini-calculators have become so readily available.

Portraying data would seem simple and unimportant. This is not so. An outstanding plot can go far towards giving the engineer perspective and understanding of a process or an event. Yet to detect the significant information, a good portrayal is often required. Outstanding plots thus usually result from several cycles of plotting, studying, replotting and so on.

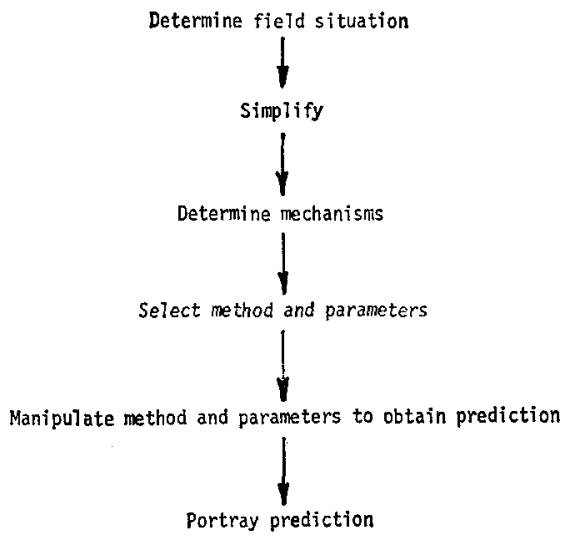

Fig. 2. Prediction process 
Even though the preceding dissection of the prediction process is helpful, the individual components of the process are seldom discrete isolated steps. A later section emphasizes the very close interrelationship that can exist between methods and data. Frequently the data portion of a prediction grades into the method portion just as the fish and the fowl grade one into another in the paintings by Escher.

In considering predictions, it is helpful to classify them as in Table 3.

Table 3. Classification of prediction

\begin{tabular}{c|l|l}
\hline $\begin{array}{c}\text { Prediction } \\
\text { type }\end{array}$ & $\begin{array}{c}\text { When prediction } \\
\text { made }\end{array}$ & $\begin{array}{l}\text { Results at time } \\
\text { prediction made }\end{array}$ \\
\hline A & $\begin{array}{l}\text { Before event } \\
\text { During event }\end{array}$ & $\begin{array}{l}\text { Not known } \\
\text { K }\end{array}$ \\
B1 & $\begin{array}{l}\text { During event } \\
\text { Duwn }\end{array}$ \\
C1 & $\begin{array}{l}\text { After event } \\
\text { After event }\end{array}$ & $\begin{array}{l}\text { Not known } \\
\text { Known }\end{array}$ \\
\hline
\end{tabular}

A type A prediction of settlement, for example, would be made before construction and based entirely on data available at that time. A type B prediction of settlement would be made during the construction and would have available data obtained during the initial parts of the construction, such as measurements made during excavation, foundation construction etc. The outcome of the event being predicted may be unknown (type B) or known (type B1). A type $\mathrm{C}$ prediction is one made after the event being predicted has occurred.

The Profession is in great need of simple techniques to make type A predictions. Even though type B predictions may be helpful, they are normally not nearly as useful as type A predictions. Type $\mathrm{C}$ predictions are autopsies. Our professional literature contains the results of more type $\mathrm{Cl}$ predictions than of any other type. Autopsies can of course be very helpful in contributing to our knowledge. However, one must be suspicious when an author uses type $\mathrm{C} 1$ predictions to 'prove' that any prediction technique is correct.

There are many other types of predictions, examples of which are predictions where the predictor has inside information, and predictions where the predictor has some control over the outcome (for example, completion date of a project). Often an 'assumption' is a prediction with little or no basis. Further, a 'surprise' can result from inaccurate predictions or the absence of a prediction.

\section{INTERRELATIONSHIP OF METHODS AND DATA}

For one to make optimum use of a process it is necessary to understand the process. The historical approach of the engineer to understanding and improving a process is to dissect the process into its components, and then to study and improve each component. During recent years we have seen that this approach can lead to improving the components of the process but unfortunately results in components that do not fit well together. The whole, i.e. the 'system', suffers even though the components improve. Systems engineering attempts to integrate the components to the benefit of the entire system. The US Space Program, especially the manned space part, dramatically emphasizes the importance of integrating the components of a process or an activity.

A concern for the deleterious effects of isolating components of a civil engineering project led me to propose the 'Integrated Civil Engineering Project' (Lambe, 1972). The principle of this approach consists of integrating the components of the project in order to obtain a constructed facility that best meets the specified criteria. 


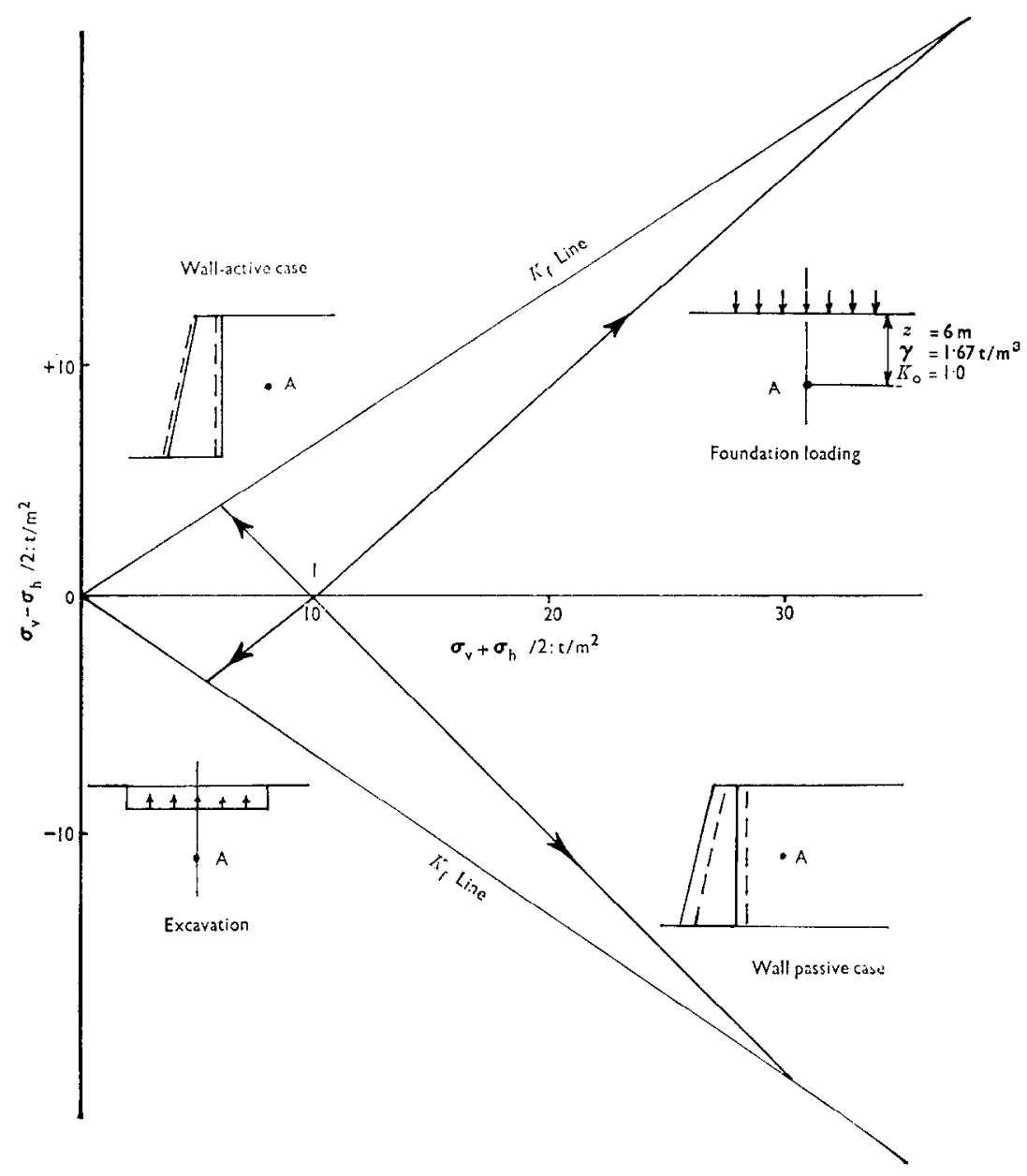

Fig. 3. Stress paths for element $\mathbf{A}$

We find a similar need for integration in making predictions. One would hope that in predicting the performance of constructed facilities, precise data could be combined with scientifically derived methods to obtain precise predictions. The soil engineer knows that this hope remains an unrealistic dream. The principles of soil mechanics clearly show that the engineering properties of soil are not unique values but in fact depend upon many variables. Both the methods and data components of a prediction depend upon the mechanism. The 'Stress Path Method' (Lambe, 1967) emphasizes this dependence. Since strain, pore water pressure and strength of a soil element depend on stress path, the engineer should consider field stress paths in selecting soil testing procedures and methods of prediction for any given problem. Fig. 3 shows stress paths for a typical soil element (element A) in four common soil engineering situations, and illustrates the widely known fact that the strength of a soil can depend very considerably on the nature of the problem. For example, the drained strength of a typical soil element in a foundation loading can be five times the corresponding strength for an unloading, such as for an excavation. 
In many techniques for predicting performance, the interrelationship between methods and data is even more complex and subtle. Nearly all soil engineering problems are statically indeterminate and the data are incomplete and inaccurate, so methods and data must be carefully matched. In other words, since many existing predictive techniques are semi-empirical the methods and data must be appropriately chosen in applying a given technique.

Schmertmann (1972) has given a number of illustrations showing the intimate interrelationship of data and methods of prediction. Using the work of Ladanyi, he showed, for example, that the term $N_{\mathrm{c}}$ in the bearing capacity equation varied from 2.5 to 7.5 when considering progressive failure of a homogeneous, sensitive clay.

The Terzaghi-Peck method of obtaining strut loads for a braced excavation well illustrates the relationship that can exist between data and method of a prediction technique. Fig. 4 (Terzaghi and Peck, 1967) shows the Terzaghi-Peck method for obtaining maximum strut loads in an excavation in soft to medium clay. The term $c$ to be used in Fig. 4 is the undrained strength of the clay. The Terzaghi-Peck method is based on field measured strut loads and undrained shear strengths as obtained from unconfined compression tests on average quality soil samples. Since the Terzaghi-Peck method was first presented, considerable evidence has been accumulated to indicate that unconfined compression tests can show strength values considerably below the strength obtained by other techniques. The engineer should not, however, expect to obtain more accurate predictions of strut loads from the Terzaghi-Peck method using undrained shear strength obtained by techniques supposedly better than the unconfined compression test. In other words, the semi-empirical Terzaghi-Peck method is derived from shear strengths as determined by the unconfined compression test. The method and data are intimately interrelated.

Figure 5 suggests that the accuracy of a prediction depends on the quality of the method as well as on the data used to make the prediction. Fig. 6 suggests an intuitive belief of mine: in making his prediction, the engineer should be consistent in the sophistication of his method of prediction and in the quality of the data employed. As shown by the dotted line, for a given method of analysis, the engineer might obtain an increasingly accurate prediction with improved data up to a given point beyond which the accuracy might deteriorate.

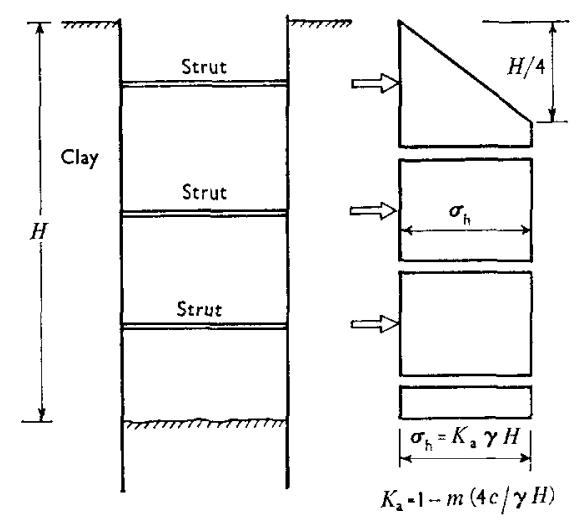

Fig. 4. Apparent lateral stress from Terzaghi and Peck (1967) 


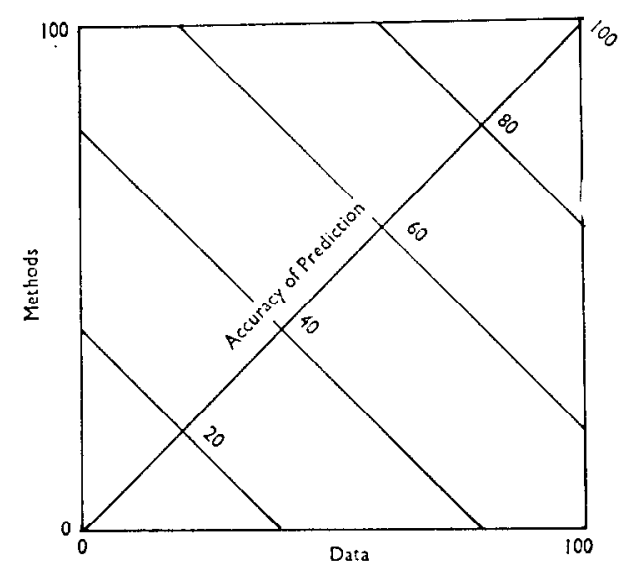

Fig. 5

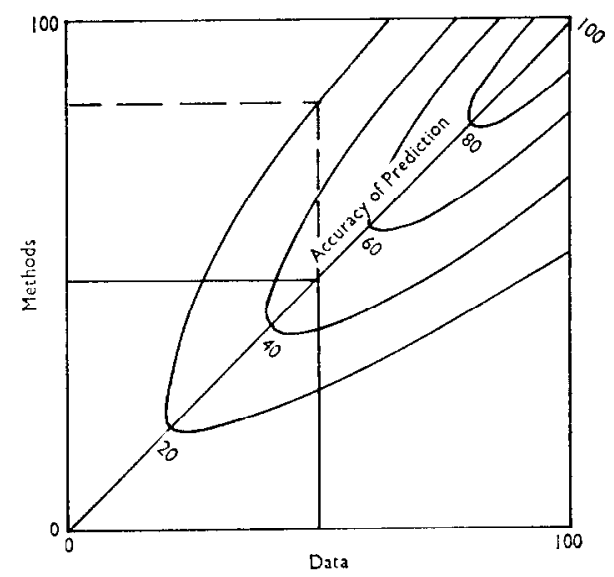

Fig. 6

Figs 5 and 6. Accuracy of prediction

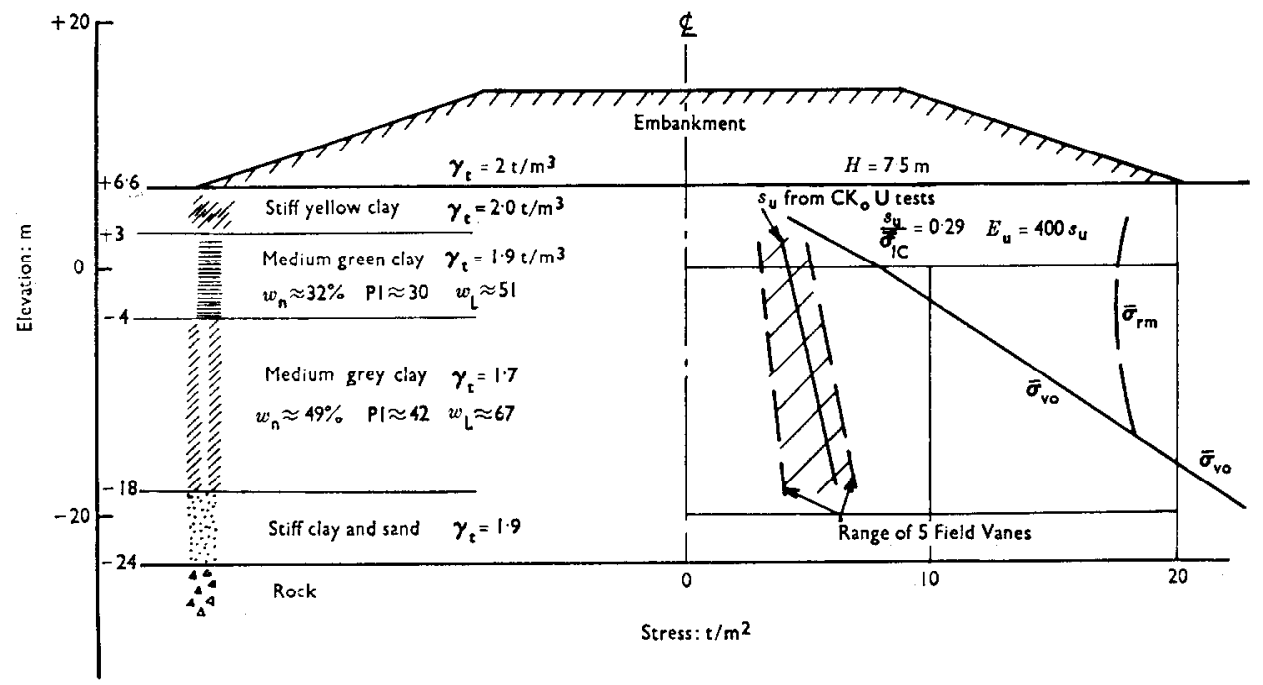

Fig. 7(a). Alibey Test Embankment

\section{ALIBEY TEST EMBANKMENT}

\section{Description}

Figure $7 \mathrm{a}$ shows a cross-section of a test embankment constructed on a clay foundation near Istanbul, Turkey. The embankment was built to permit an evaluation of the settlement and stability predictions made for the Alibey Dam. The embankment would become part of the upstream cofferdam used to divert the Alibey Creek during dam construction. Plans called for raising the test embankment to a height of 11 metres; however, performance data are available only for an embankment height of 7.5 metres.

Predictions were made of pore pressure, deformation and stability for the Alibey Dam and for the test embankment. Dugan (1968) describes soil tests, predic tions and field measure ments for the test embankment. 


\section{Stresses}

Figure $7 \mathrm{~b}$ shows measured shear strengths and calculated vertical effective stresses in the Alibey foundation. Fig. $7 \mathrm{~b}$ gives shear stress contours computed by FEAST-3, a finite element program employing bilinear elastic, stress-strain properties for an undrained plane strain condition. As can be seen, the calculated shear stresses in much of the foundation exceeded the shear strength, i.e. yielding occurs.

Figure 8 presents predicted and measured values of initial excess pore pressure under the centreline of the fill. Pore pressures measured at two clusters of instrumcntation, $40 \mathrm{~m}$ apart, are shown. Data from borings at the two cluster locations revealed similar subsoil conditions; settlements of the embankment at the two locations were within three centimetres of each other. As indicated in Fig. 8, both Skempton's method and the change in octahedral stress gave good predictions of initial excess pore pressure under the centre of the fill.

Predicted and measured pore pressures under the test embankment are shown in Fig. 9. As can be seen, Skempton's method correctly predicted that higher excess pore pressures would occur in the medium grey clay than in the stiff yellow clay. The medium grey clay received smaller increments of stress from the embankment but was softer than the yellow clay.

\section{Deformation}

Figure 10 depicts measured and predicted settlements of the base of the embankment. Two settlement predictions are shown. The first prediction, a type A prediction, was based on a value of $c_{\mathrm{v}}$ equal to $4.8 \times 10^{-4} \mathrm{~cm}^{2} / \mathrm{s}$. The value of $4.8 \times 10^{-4} \mathrm{~cm}^{2} / \mathrm{s}$ was obtained by modifying the value of $c_{\mathrm{v}}\left(2 \times 10^{-4} \mathrm{~cm}^{2} / \mathrm{s}\right)$ from oedometer tests according to the method suggested by Davis and Poulos (1965) to give an appropriate $c_{\mathrm{v}}$ for plane strain. The second prediction, a type B prediction, was based on a value of $c_{\mathrm{v}}=120 \times 10^{-4} \mathrm{~cm}^{2} / \mathrm{s}$, a value inferred from the dissipation of pore pressures measured by the field piezometers. Note that the inferred value of $c_{\mathrm{v}}$ is 25 times the laboratory value.

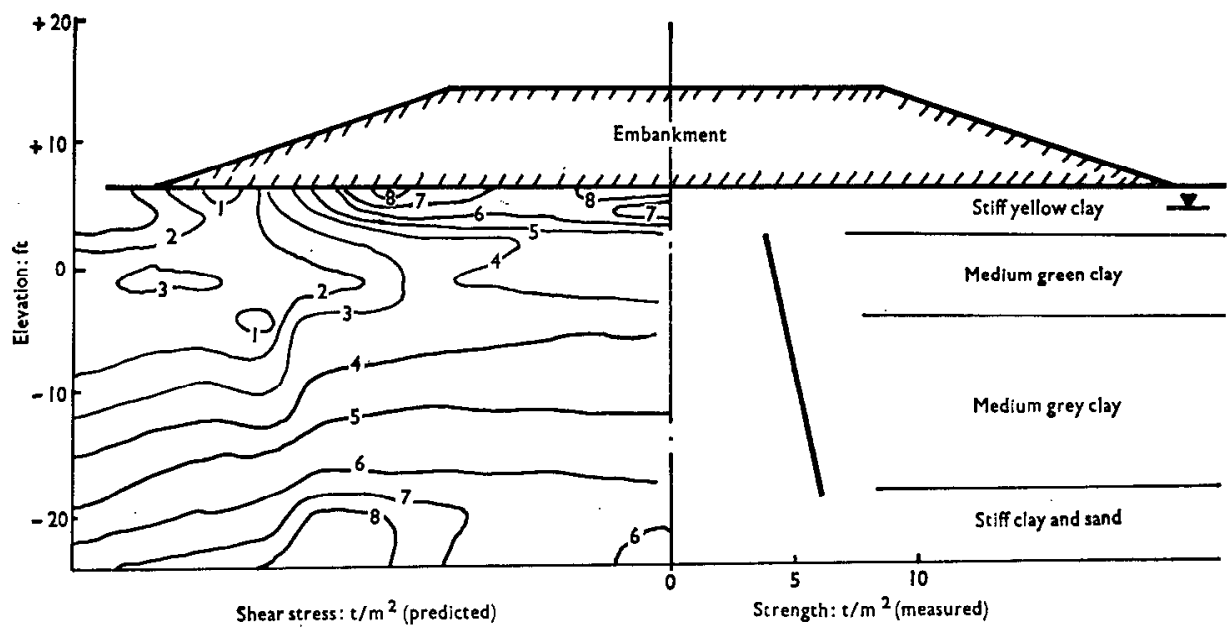

Fig. 7(b). Predicted stresses and measured shear strength in foundation 


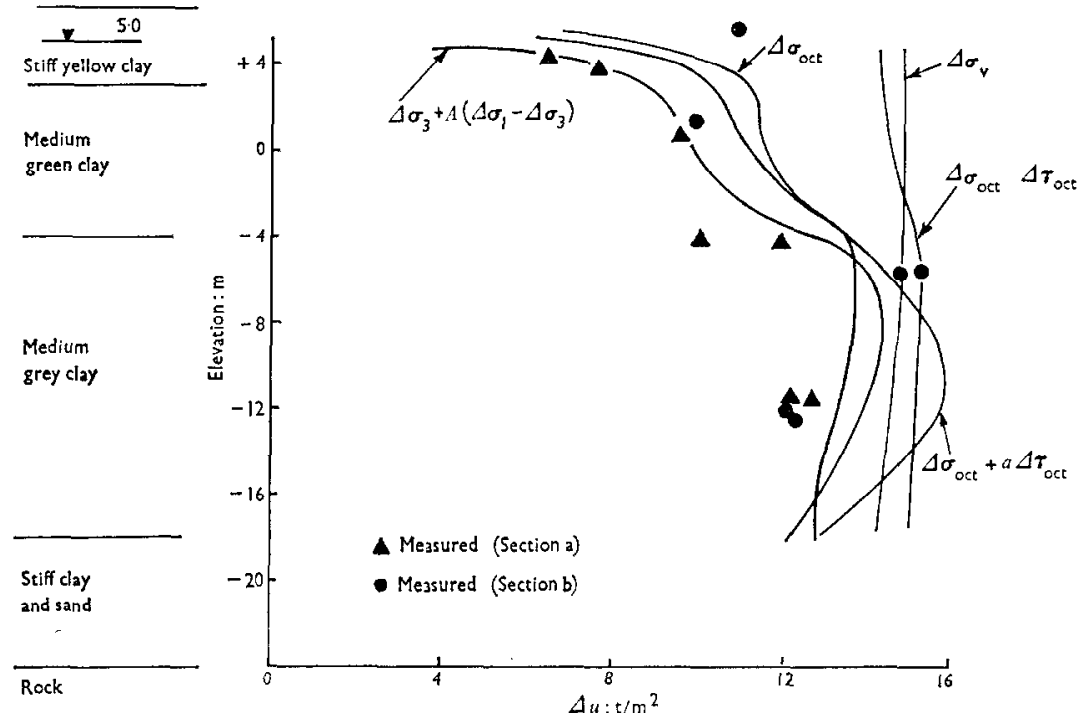

Fig. 8. Initial pore pressures under centreline of fill

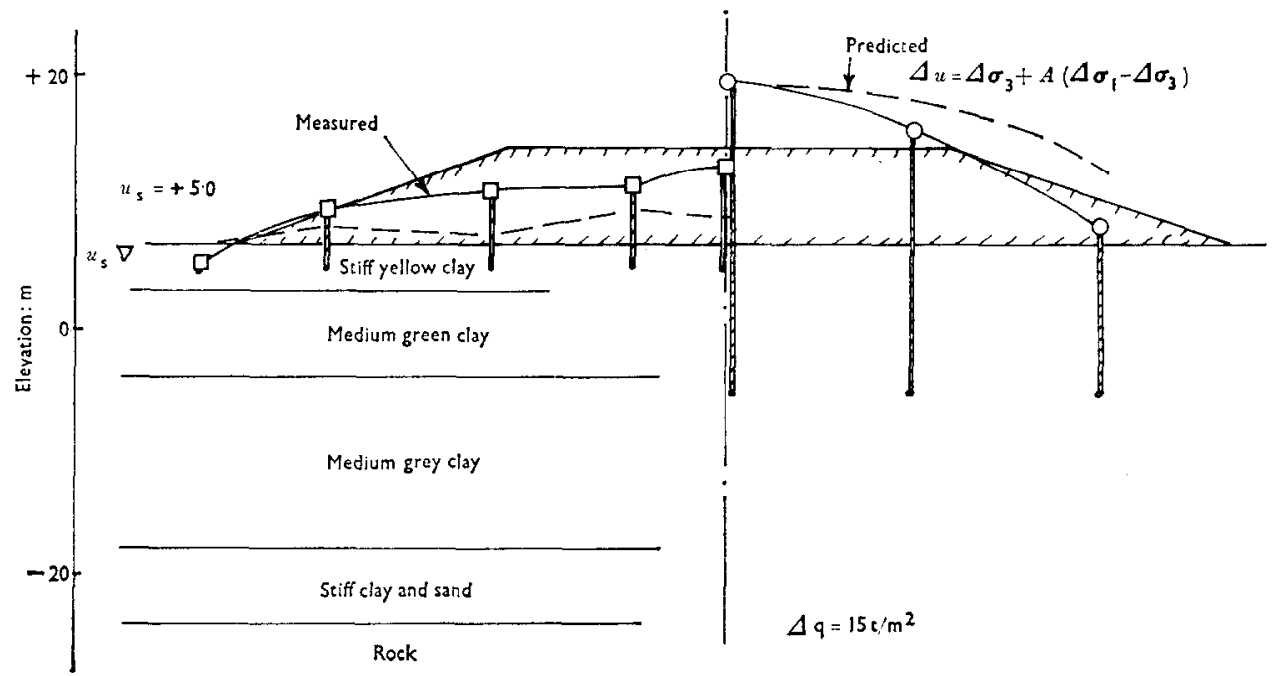

Fig. 9. Initial total head 


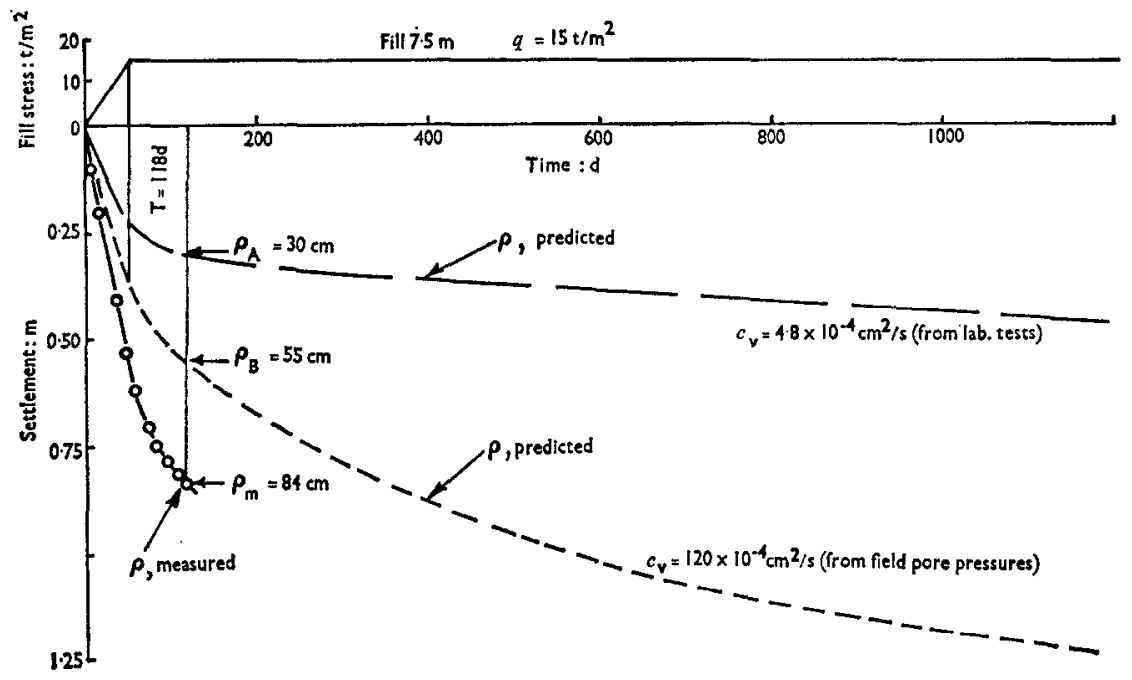

Fig. 10. Embankment settlement

Table 4 compares predicted and measured settlements. As indicated in Fig. 10 and Table 4 the settlement at the end of loading and the settlement at the end of 118 days were both grossly underpredicted.

The Alibey foundation clays are highly stratified and contain from $2 \%$ to $5 \%$ organic matter. The major clay species is a highly expansive montmorillonite. All the clay samples examined contained lenses of silt and shell fragments. Analyses of pore fluid from the clays indicated less than $1 \mathrm{~g} / \mathrm{l}$ of salt for samples above a depth of about $7 \mathrm{~m}$, whereas the deeper samples had 4-12 g of salt per litre of pore fluid. The silt and shell lenses probably caused the scatter in shear strength values and caused much greater lateral permeability than vertical permeability. The silt and shell layers probably helped account for the underprediction of settlement rate, as discussed by Rowe (1972).

\section{Stability}

What undrained shear strength should be used to predict the stability of the Alibey Dam for the end of loading? Both laboratory tests on undisturbed samples and field vane tests gave a large variation in undrained strength.

A stability analysis based on Bishop's modified method of slices and undrained strengths from triaxial tests (see Fig. 7) gave a factor of safety of $1 \cdot 7$. Using the expression $q_{\mathrm{u}}=5 \cdot 1 s_{\mathrm{u}}$ resulted in a factor of safety of 1.0 for the lowest and a factor of safety of 2.4 for the highest undrained shear strengths measured by the field vane.

Table 4. Settlement in centimetres

\begin{tabular}{l|c|c}
\hline & End of loading & At 118 days \\
\hline Predicted-type A & 22 & 30 \\
Predicted-type B & 37 & 55 \\
Measured & 53 & 84 \\
\hline
\end{tabular}


Fig. 11 (right). Locations of test embankments

Fig. 12 (below). Northeast Test Embankment
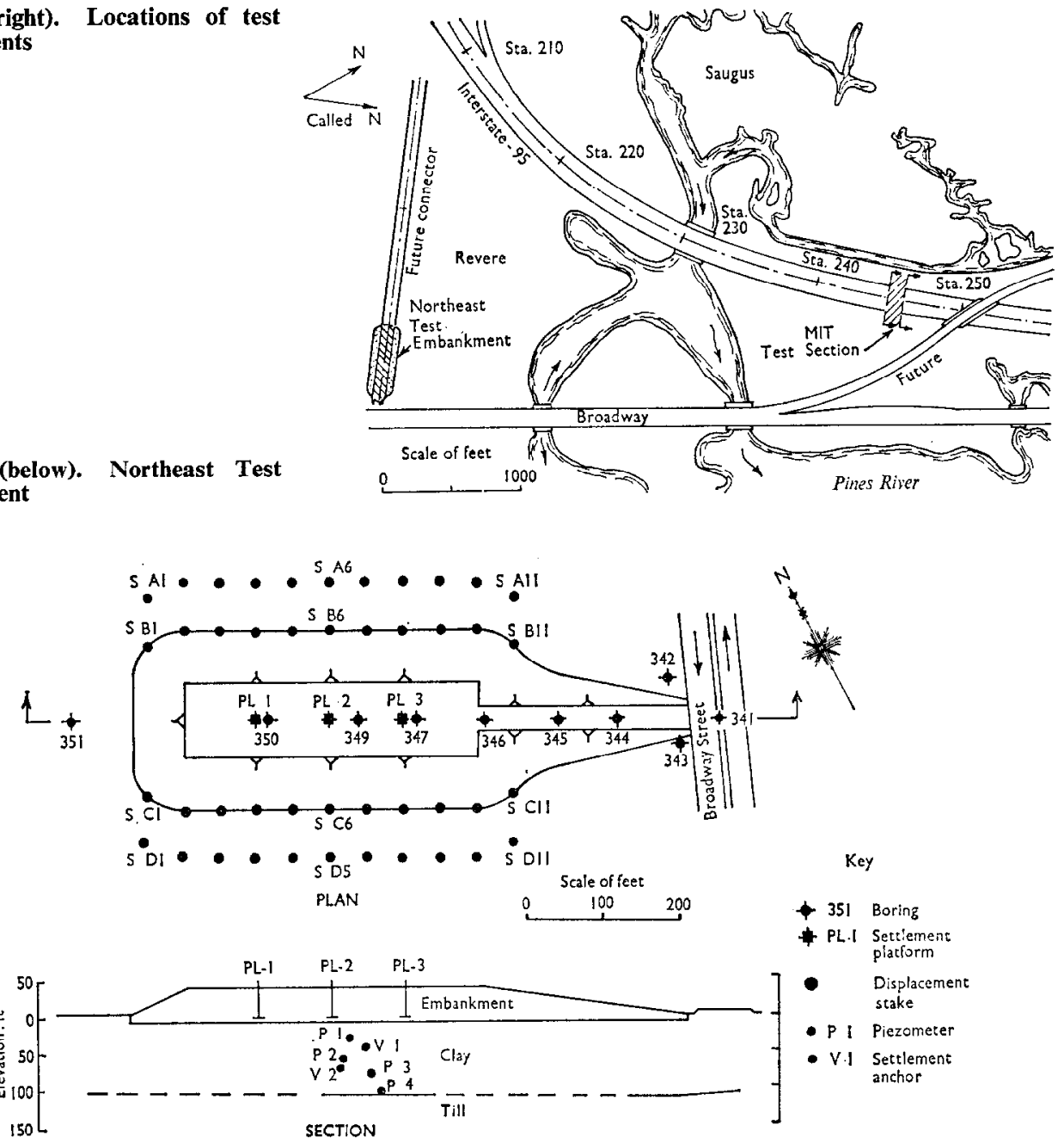

As the embankment did not cause a failure of the foundation, the factor of safety against a shear failure was obviously greater than unity. Further, since the embankment was later raised to a height of $11 \mathrm{~m}$, a factor of safety of 1.3 or greater is suggested for the situation shown in Fig. 7.

\section{NORTHEAST TEST EMBANKMENT}

\section{Description}

A half-mile section of Interstate Highway I-95 passes through a tidal marsh in the RevereSaugus area north of Boston, Massachusetts. In 1957 a test embankment, Northeast Test Embankment, was constructed along the proposed route of a connector to I-95. In June 1965, MIT began a research project along the main route for I-95. Fig. 11 locates the Northeast Test Embankment, described in this section, and the MIT Test Section, described subsequently. 
Figure 12 shows a plan and section of the Northeast Test Embankment. The embankment crest is at elevation $+40 \mathrm{ft}$ (elevation zero equals mean sea level) and is $100 \mathrm{ft}$ wide and $400 \mathrm{ft}$ long. The soil profile at both the Northeast Test Embankment and MIT Test Section consists of silt, peat and sand overlying a thin layer of stiff yellow clay which in turn overlies a thick layer of medium to soft Boston Blue Clay. Below the clay is till. The silt and peat were removed before construction of both embankments. Figs 13 and 14 show the results of tests on the subsoil. The Northeast Embankment case is described by Lambe et al. (1972).
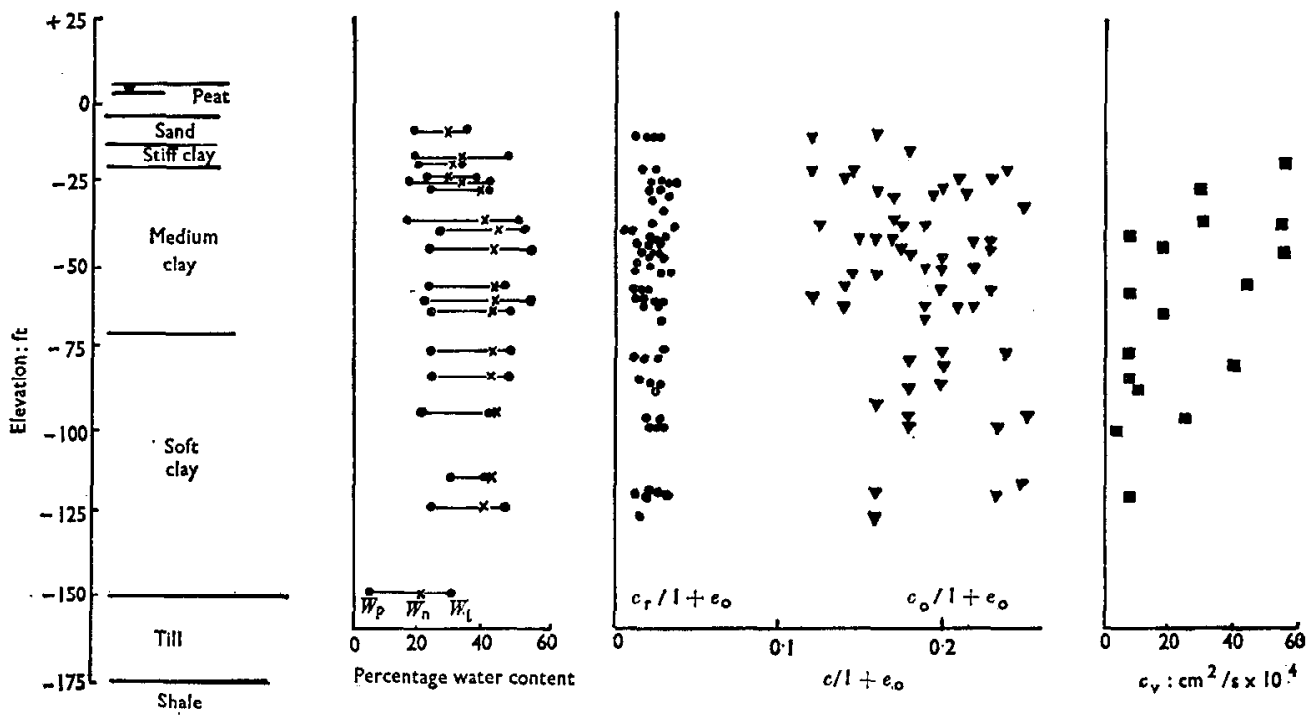

Fig. 13 (above) and Fig. 14 (below). Subsoil properties
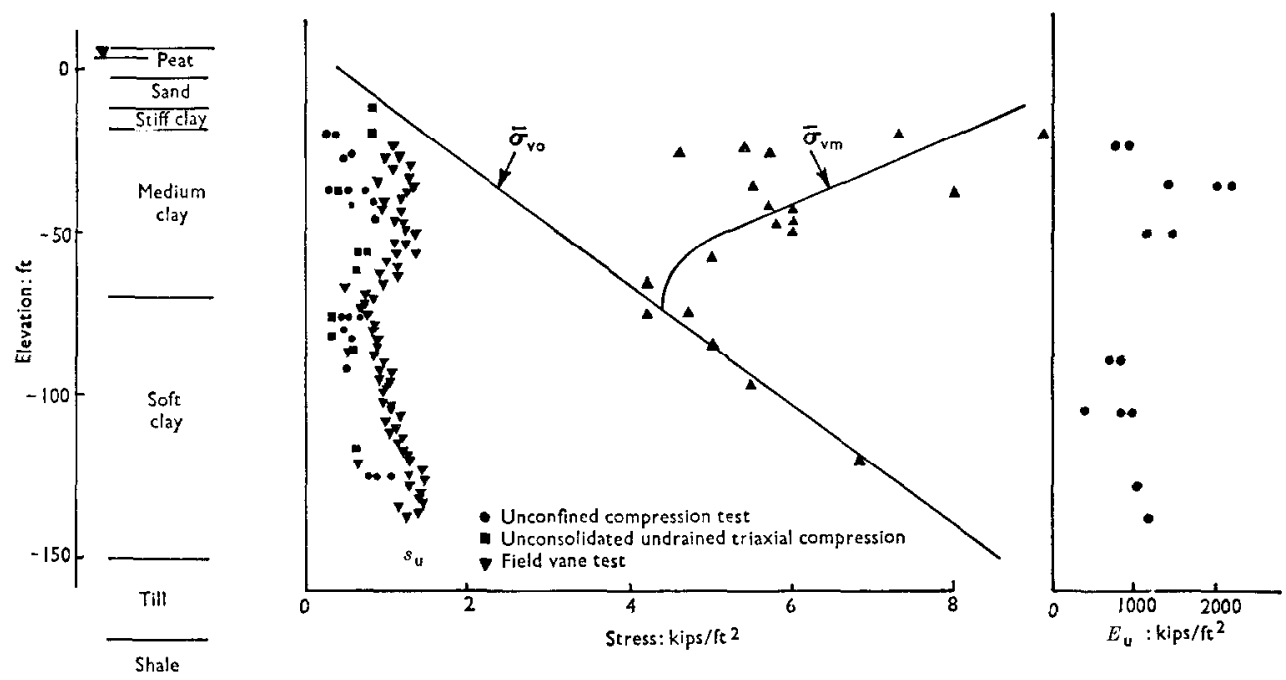


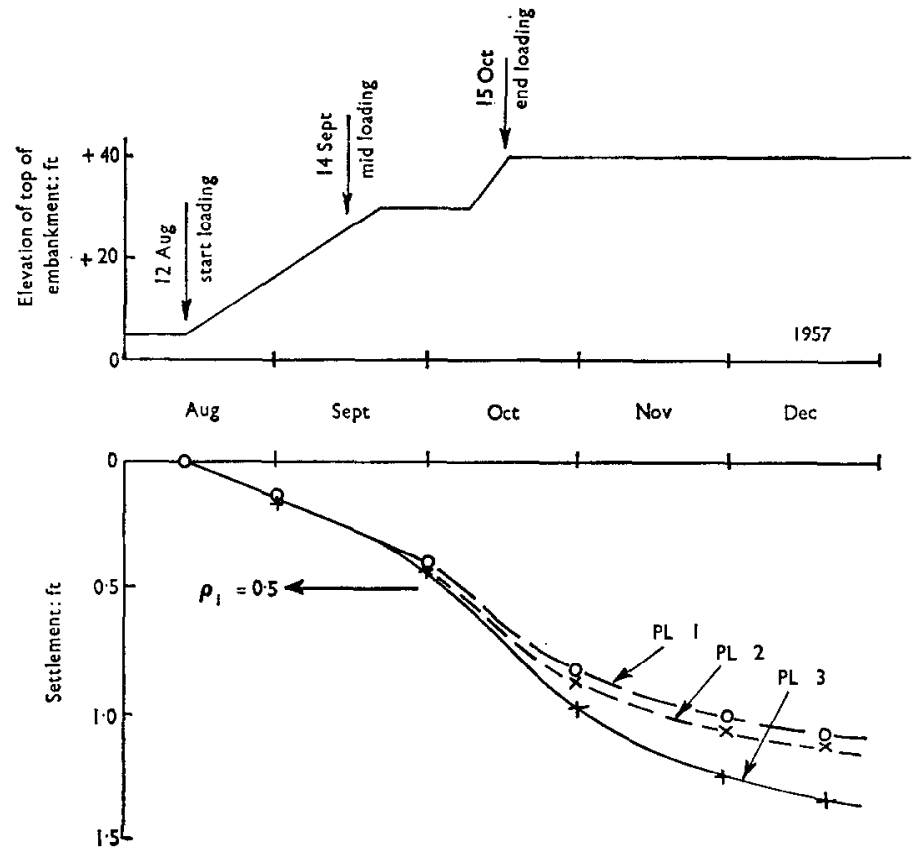

Fig. 15. Early settlement

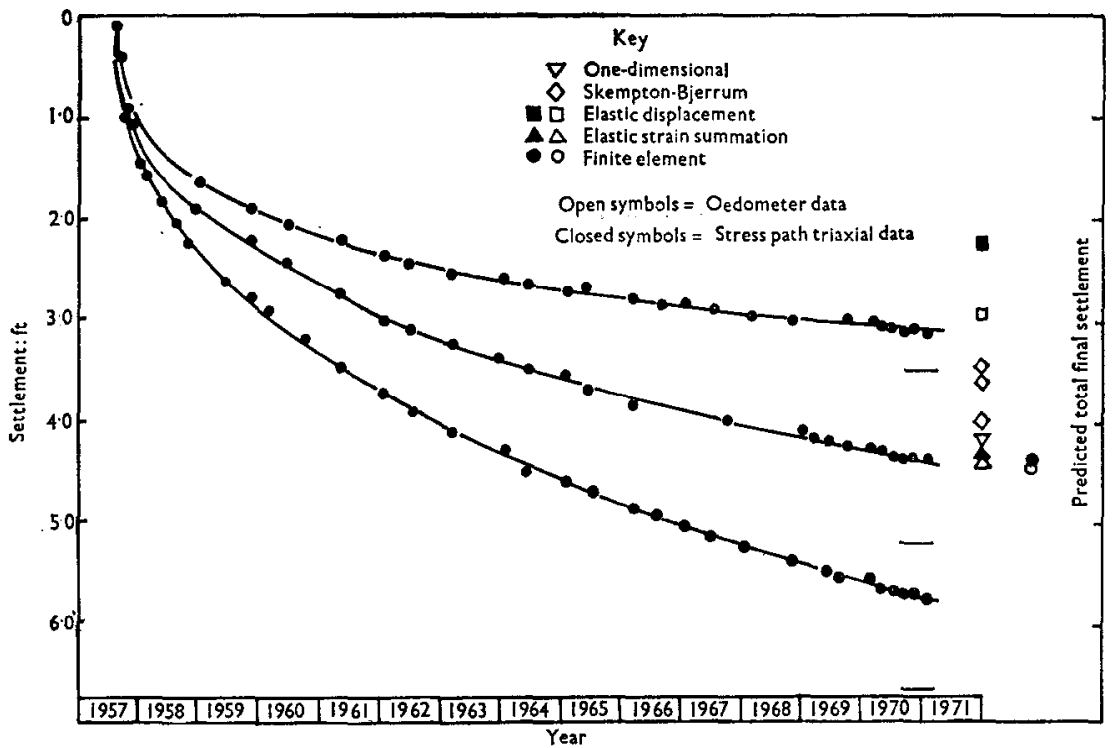

Fig. 16. Embankment settlement 

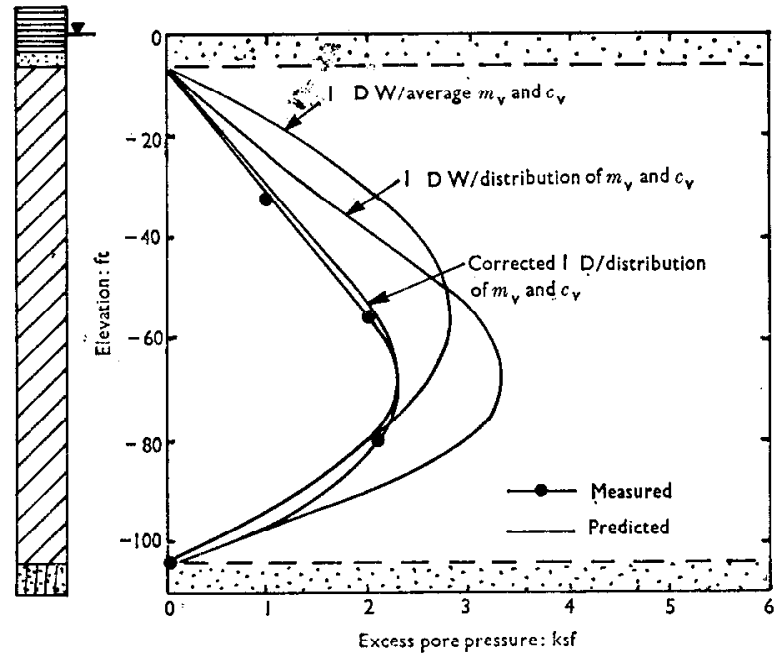

Fig. 17. Pore pressure dissipation

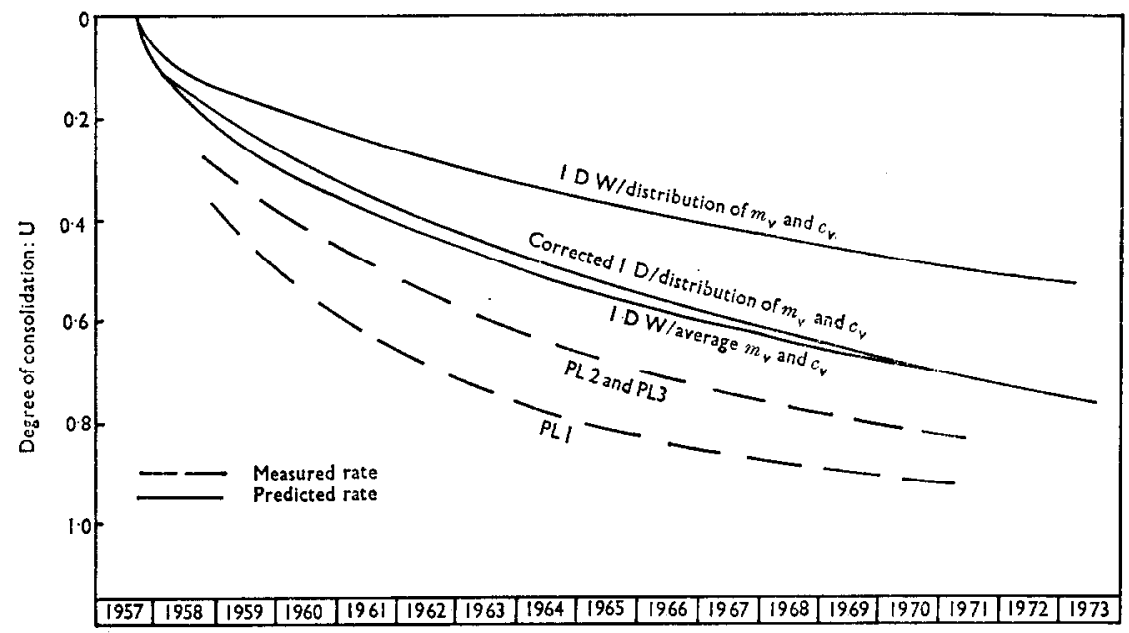

Fig. 18. Degree of consolidation

\section{Deformations}

Figures 15 and 16 show embankment settlement data, Fig. 17 shows pore pressure data, and Fig. 18 shows degree of consolidation.

As indicated in Fig. 15, the initial settlement of the embankment equals $0.5 \mathrm{ft}$. Tables 5 and 6 give predicted initial settlement (type $\mathrm{Cl}$ predictions). A comparison of predicted and measured initial settlements suggests that the less sophisticated techniques gave the most accurate predictions. 
Table 5. Methods of predicting initial settlement

\begin{tabular}{l|c|c}
\hline \multicolumn{1}{c|}{ Method } & Formula & \multicolumn{1}{c}{ Reference } \\
\hline Elastic displacement & $\rho_{\mathrm{l}}+\frac{q B I}{E_{\mathrm{u}}}$ & Skempton and Bjerrum (1957) \\
Elastic strain summation & $\rho_{\mathrm{1}}=\Sigma\left[\frac{\sigma_{\mathrm{z}}+\frac{1}{2}\left(\sigma_{\mathrm{x}}+\sigma_{\mathrm{v}}\right)}{E_{\mathrm{u}}}\right] \Delta \mathrm{Z}$ & Davis and Poulos (1968) \\
Modified elastic displacement & $\rho_{1}=S_{\mathrm{R}}\left(\frac{q B I}{E_{\mathrm{u}}}\right)$ & D'Appolonia et al. (1970) \\
Finite element & By computer $\left(E_{\mathrm{u}}, S_{\mathrm{u}}, \bar{\sigma}_{\mathrm{v} 0}, \bar{\sigma}_{\mathrm{h} 0}\right)$ & D'Appolonia and Lambe (1970) \\
\hline
\end{tabular}

Table 6. Predicted initial settlement

\begin{tabular}{l|c|c|c}
\hline \multicolumn{1}{c|}{ Method } & \multicolumn{3}{|c}{ Predicted initial settlement, $\mathrm{ft}$} \\
\cline { 2 - 3 } & $\begin{array}{c}E_{\mathrm{u}} \text { from } \\
\text { UU tests }\end{array}$ & $\begin{array}{c}E_{\mathrm{u}} \text { from } \\
\mathrm{CK}_{\mathrm{o}} \mathrm{U} \text { tests }\end{array}$ & $\begin{array}{c}E_{\mathrm{u}} \text { from } \\
E_{\mathrm{u}} / S_{\mathrm{u}}=1200\end{array}$ \\
\hline Elastic displacement & 0.61 & 0.15 & 0.09 \\
Elastic strain summation & 0.61 & 0.13 & 0.08 \\
Modified elastic displacement & Failure & 0.22 & 0.12 \\
Finite element & Failure & 0.21 & 0.11 \\
\hline
\end{tabular}

Table 7. Methods of predicting total final settlement

\begin{tabular}{l|l|l}
\hline \multicolumn{1}{c|}{ Method } & \multicolumn{1}{c|}{ Formula } & \multicolumn{1}{c}{ Reference } \\
\hline One-dimensional & $\rho_{\mathrm{TF}}=\rho_{\mathrm{t}}+\rho_{\mathrm{oed}}$ & Terzaghi (1943) \\
Skempton-Bjerrum & $\rho_{\mathrm{TF}}=\rho_{\mathrm{i}}+\mathrm{u} \rho_{\rho_{\mathrm{ed}}}$ & Skempton and Bjerrum (1957) \\
Elastic displacement & $\rho_{\mathrm{TF}}=q B I(1-\nu)^{2} / \bar{E}$ & Davis and Poulos (1968) \\
Elastic strain summation & $\rho_{\mathrm{TF}}=\Sigma\left[\bar{\sigma}_{\mathrm{Z}}-\bar{v}\left(\bar{\sigma}_{\mathrm{x}}-\bar{\sigma}_{\mathrm{u}}\right) / \bar{E}\right] \Delta \mathrm{Z}$ & Davis and Poulos (1968) \\
Finite element & By computer $(\bar{E}, \nu)$ & \\
\hline
\end{tabular}

Table 8. Predicted total final settlement

\begin{tabular}{|c|c|c|c|}
\hline \multirow[t]{2}{*}{ Method } & \multicolumn{3}{|c|}{ Predicted total final settlement, $\mathrm{ft}$} \\
\hline & & meter data & $\begin{array}{l}\bar{E}, \bar{y} \text { from stress } \\
\text { path triaxial tests }\end{array}$ \\
\hline $\begin{array}{l}\text { One-dimensional } \\
\text { Skempton-Bjerrum } \\
\text { Elastic displacement } \\
\text { Elastic strain summation } \\
\text { Finite element }\end{array}$ & $3 \cdot 38$ & $\begin{array}{ll}4 \cdot 10 & \\
3 \cdot 55 & 3.92 \\
2 \cdot 90 & \\
4 \cdot 31 & \\
4 \cdot 36 & \end{array}$ & $\begin{array}{l}\overline{-} \\
2 \cdot 19 \\
4 \cdot 23 \\
4 \cdot 33\end{array}$ \\
\hline
\end{tabular}

Table 9. Methods of predicting rate of settlement

\begin{tabular}{l|l}
\hline \multicolumn{1}{c|}{ Method } & \multicolumn{1}{c}{ Reference } \\
\hline 1. 1-D strain and drainage average $m_{\mathrm{v}}$ and $c_{\mathrm{v}}$ & Terzaghi (1943) \\
2. 1-D strain and drainage distribution of $m_{\mathrm{v}}$ and $c_{\mathrm{v}}$ & $\begin{array}{l}\text { Schiffman and Gibson (1967) } \\
\text { Davis (1969) }\end{array}$ \\
3. 1-D strain and 2-D drainage distribution of $m_{\mathrm{v}}$ and $c_{\mathrm{v}}$ & \\
\hline
\end{tabular}


Figure 16 presents embankment settlements at the three settlement plates. Also plotted in Fig. 16 are predicted total final settlements obtained by the methods noted in Tables 7 and 8 .

Figures 17 and 18 compare predicted and measured excess pore pressure and rate of settlement made according to the methods noted in Table 9.

\section{Discussion}

The Northeast Test Embankment case illustrates the following important points.

(a) Scatter in soil properties: Figs 14 and 15 show a large scatter in soil properties.

(b) Type $\mathrm{C} 1$ prediction: the engineer can always find some method and some set of data which will give an accurate prediction of excess pore pressure. See, for example the prediction made by the 'corrected' one-dimensional technique with a distribution of $m_{\mathrm{v}}$ and $c_{\mathrm{v}}$ (see Fig. 17).

(c) Sophisticated analyses: as shown by the comparison of predicted and measured initial settlements, the engineer should not be influenced by the sophistication of his prediction techniques. The simplest technique employed gave the most accurate prediction of initial settlement for the Northeast Test Embankment.

(d) Unpredictability: soils sometimes behave in an apparently unpredictable fashion. As seen in Fig. 16, there are very large and unexplained differences in settlements occurring at the three different settlement plates. Considerable time and effort were expended in an unsuccessful attempt to explain the different settlement behaviour at the three plates. I conclude that the most probable explanation for this variation in settlement behaviour lies in differences in the foundation conditions at the three locations of the plates. This could not be proved. Any of the three settlement curves in Fig. 16 could be closely predicted by a type $\mathrm{Cl}$ prediction with appropriate selection of soil parameters. One must surely refrain from concluding that any particular predictive technique is correct merely because it accurately predicts settlement at one location.

\section{MIT TEST SECTION}

\section{Description}

The location of the MIT Test Section and the properties of the subsoils were described in the preceding chapter on the Northeast Test Embankment. Wolfskill and Soydemir (1971) and D'Appolonia et al. (1971) describe certain aspects of the MIT Test Section. Fig. 19 shows plan and section views through the section and locates the field instrumentation.

\section{Stresses}

Figure 20 compares predicted and measured total vertical stresses within the embankment when its crest had reached elevation $+40 \mathrm{ft}$. The predicted total vertical stresses are type $\mathrm{C} 1$ predictions. The total unit weights used in the predictions were field measured values.

D'Appolonia et al. (1971) published an evaluation of pore pressures in the foundation at the MIT Test Section. The measured pore pressures in the foundation, especially in the region from -55 to $-80 \mathrm{ft}$ elevation, showed considerable variation-about $\pm 25 \%$ of the average value. In general the excess pore pressures at a point increased linearly with increasing embankment height until a certain critical height was reached; subsequently a further linear increase in excess pore pressure with embankment height occurred, but at a greater rate. Presumably the change in the plot of excess pore pressure against embankment height occurred when the shear strength of the foundation had been reached and local yield had occurred. 


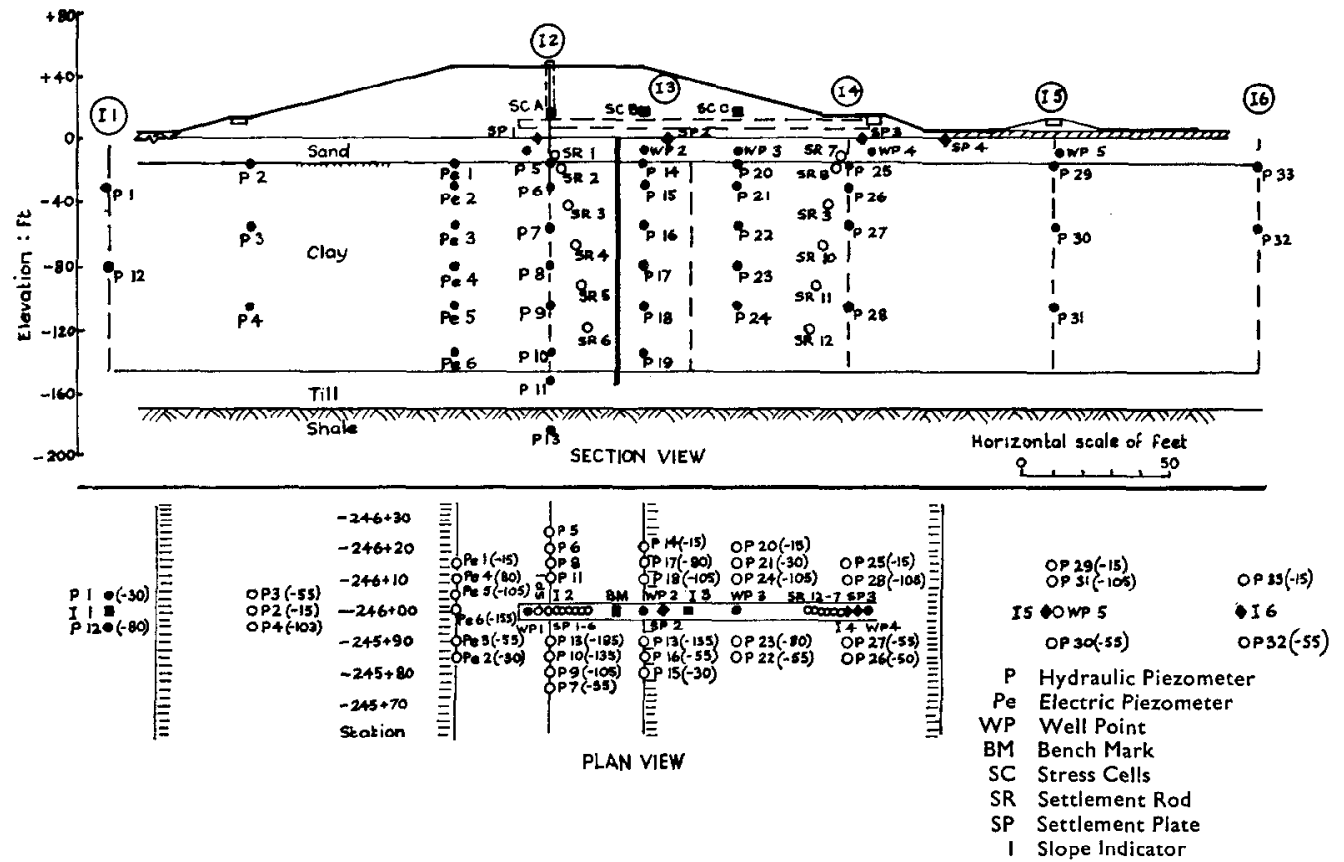

Fig. 19. MIT test section instrumentation
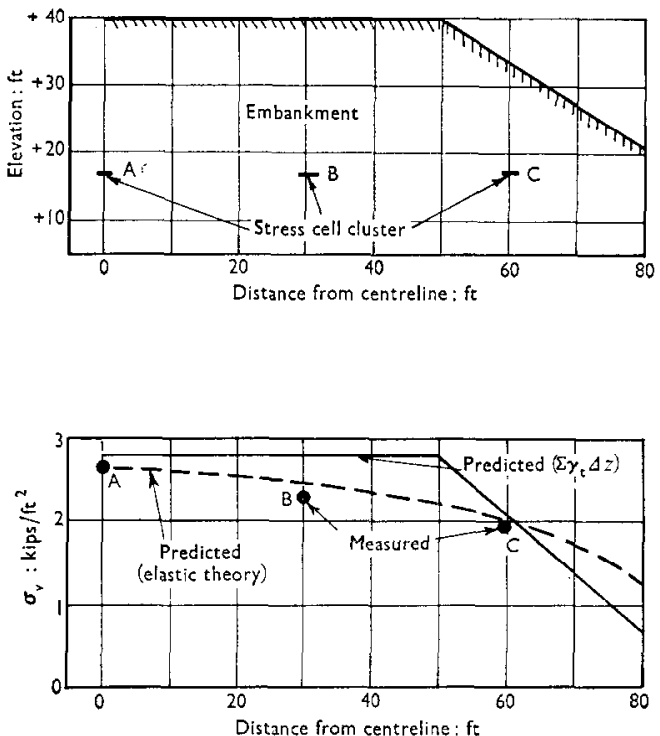

Fig. 20. Vertical stress in cmbankment 

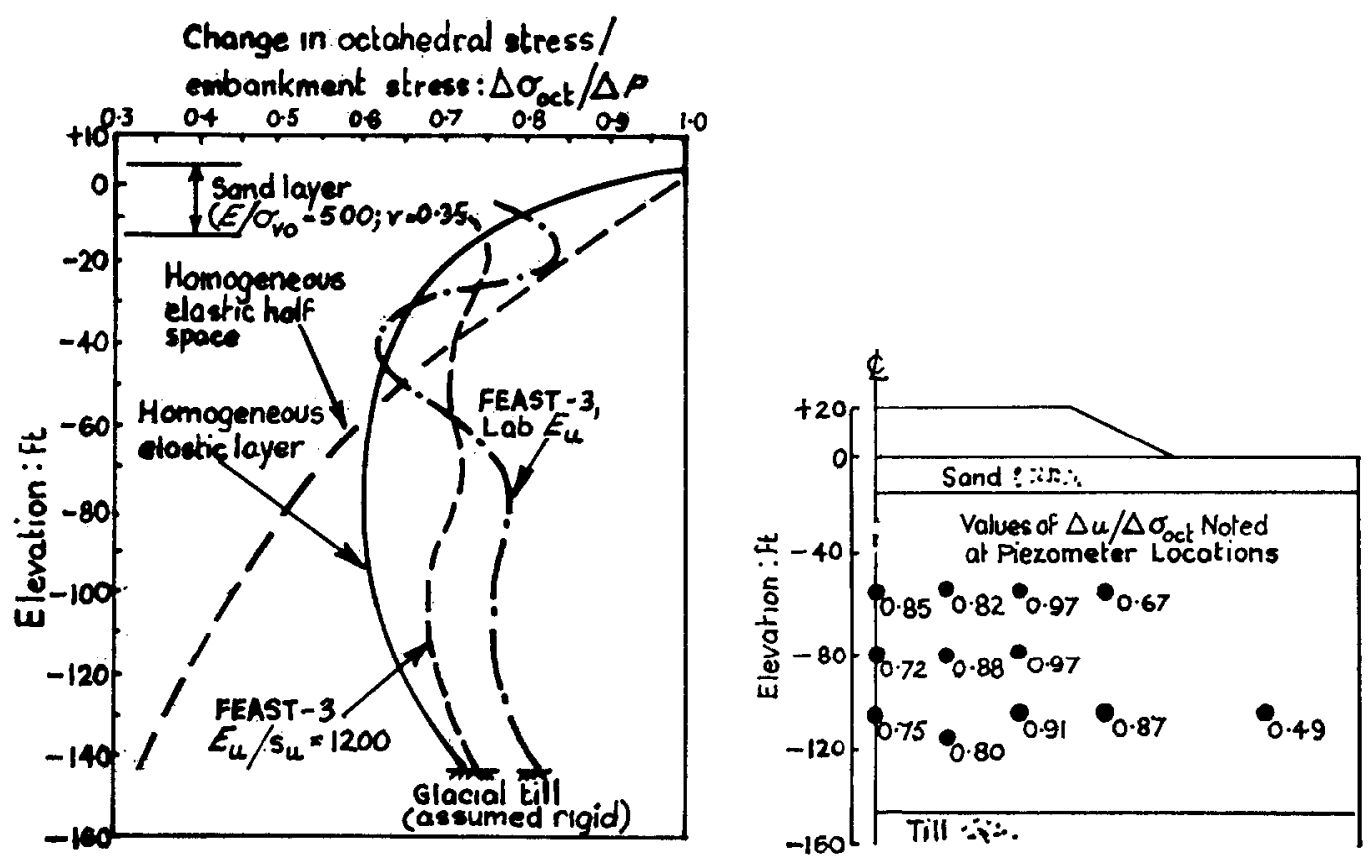

Fig. 21. Predicted total stress changes

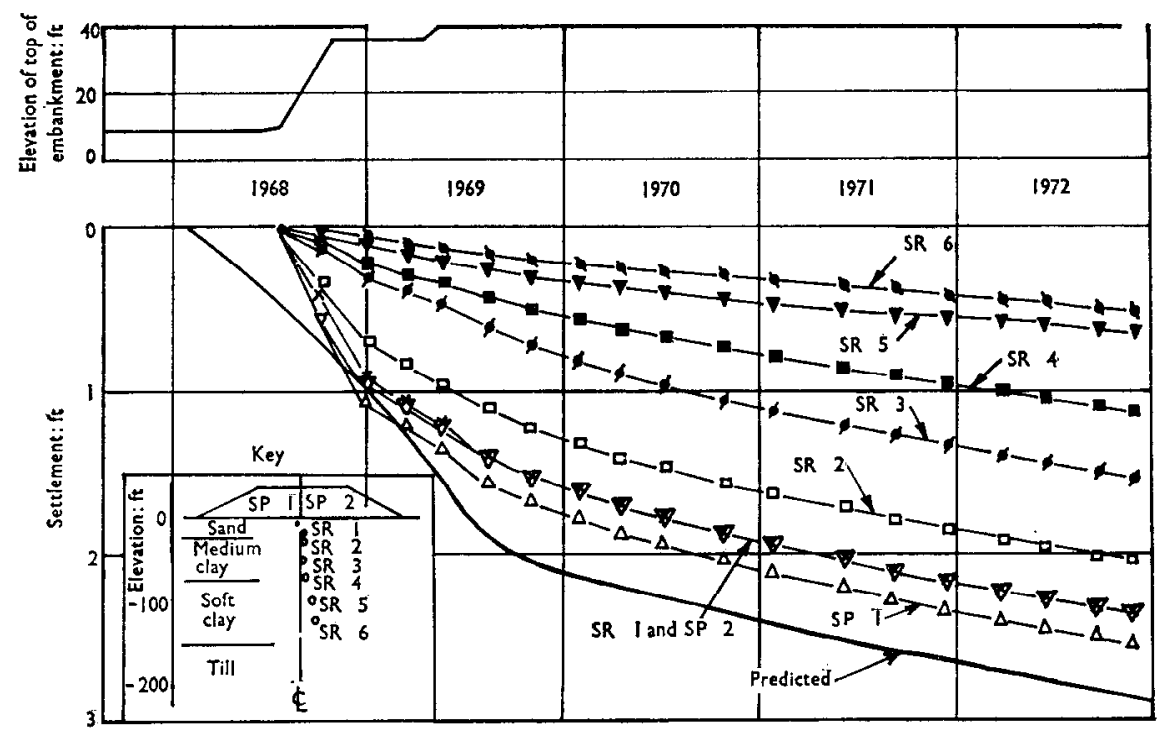

Fig. 22. Settlement at MIT test section 
Prior to local yield, the excess pore pressures were approximately equal to the change in octahedral normal stress. After yield, the incremental change in excess pore pressure was approximately equal to the incremental change in the major principal stress.

Predictions of excess pore pressure in the foundation are based on predictions of increments of total stress induced in the foundation by the applied surface load. As can be seen by Fig. 21 (D'Appolonia et al., 1971) the different methods of predicting total stress increments in the foundation yield widely different values. Curve 4 was used in predicting pore pressures in the foundation.

\section{Deformations}

Figure 22 shows settlement as a function of time for a number of points at the centre line of the embankment. Also shown in Fig. 22 is a predicted time-settlement curve (type A prediction).

A large number of deformation and stability predictions was made. Essentially every known predictive technique was employed in predicting deformations of the MIT Test Section (see Table 10 for a listing of methods of predicting settlement). All of these predictions were type $\mathrm{Cl}$ predictions.

Table 10. Methods of predicting initial excess pore pressure

\begin{tabular}{l|l}
\hline \multicolumn{1}{c|}{ Method } & \multicolumn{1}{c}{ Equation } \\
\hline $\begin{array}{l}\text { One-dimensional } \\
\text { Three-dimensional elastic }\end{array}$ & $\Delta_{u}=\Delta \sigma_{\mathrm{v}}$ \\
$\begin{array}{l}\text { Skempton's equation } \\
\text { Henkel's equation }\end{array}$ & $\Delta u=\Delta \sigma_{\text {oct }}$ \\
& $\Delta u=\Delta \sigma_{\text {oct }}+a \Delta \tau_{\text {oct }}$ \\
\hline
\end{tabular}

The plotted deformation data (Fig. 23) portray the nature and magnitude of deformations which occurred in the foundation. As these plots show, during both loading and consolidation not only vertical movements but also significant lateral movements occurred. In other words, the strains in the foundation were far from one-dimensional. Further, the total heads, Fig. 24, indicate that considerable lateral flow of pore water occurred.

Figure 25 compares predicted and measured lateral deformations in the foundation at the toe of the embankment. Finite element analyses were used to predict lateral deformations. The analyses tended to underpredict lateral deformation in the upper foundation soil and overpredict lateral movement below an elevation of about $-40 \mathrm{ft}$.

Figure 26 compares measured deformations at the end of embankment construction with those predicted by FEAST-3. The analyses underpredicted settlement but gave reasonably good predictions of lateral deformation.

\section{Stability}

Stability for the MIT Test Section was an important consideration. Analyses by the consulting engineer on the I-95 project indicated that the embankment could not be built to an elevation of $+40 \mathrm{ft}$ because a shear failure would occur through the foundation. The main problem encountered in making stability predictions for the test section is deciding on the appropriate undrained shear strength to be used in the analyses. Fig. 27 shows strengths of the foundation clay as measured by laboratory tests and field tests, and strengths inferred 

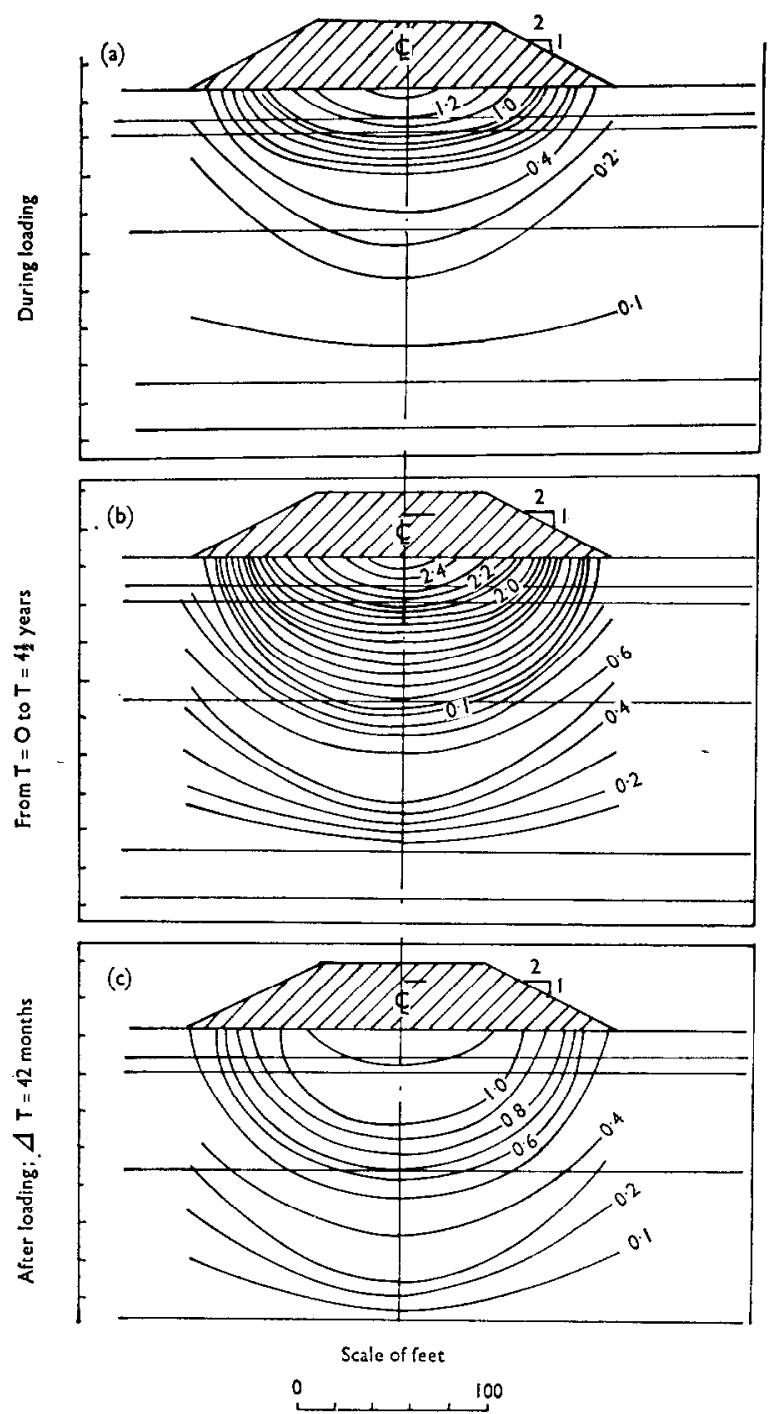

Fig. 23. Lines of equal settlement 


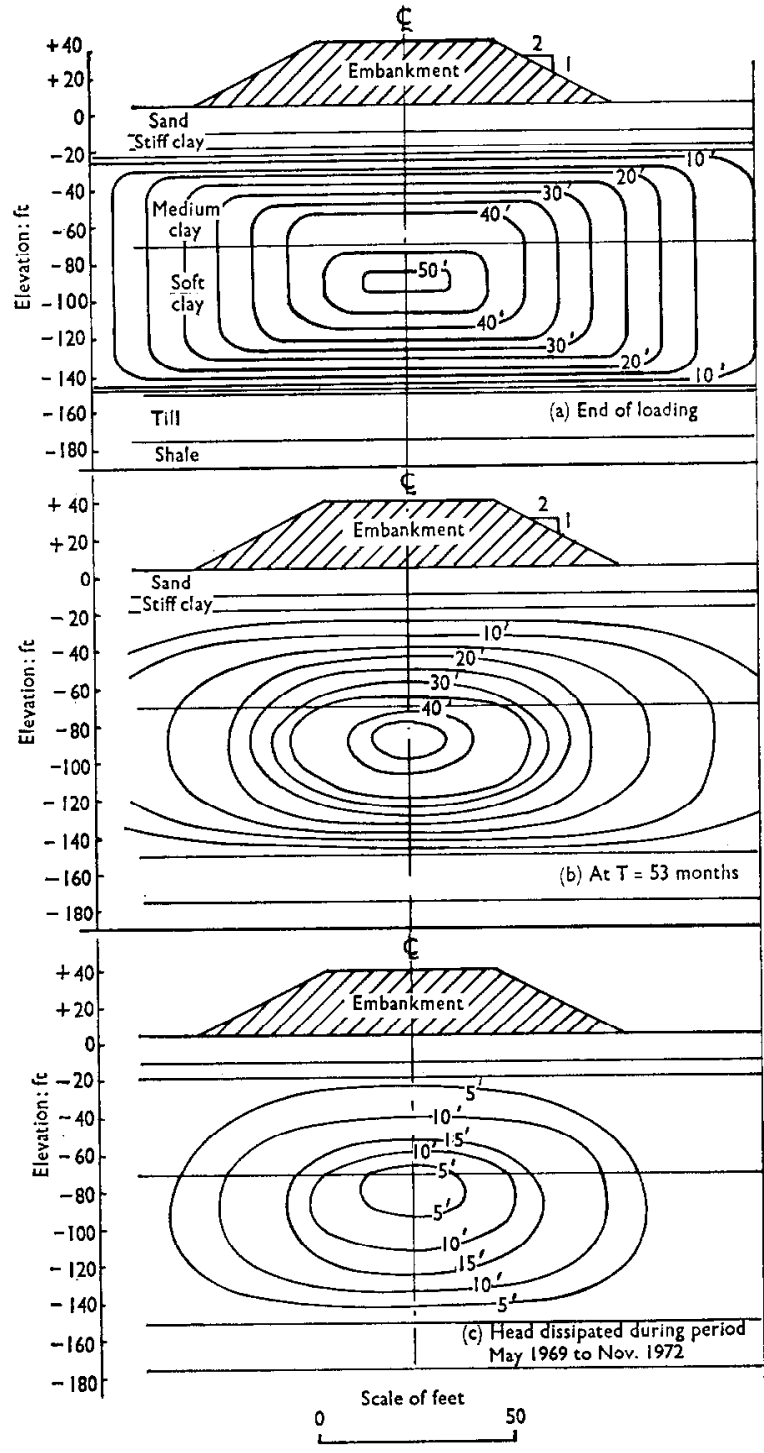

Fig. 24. Lines of equal total head 

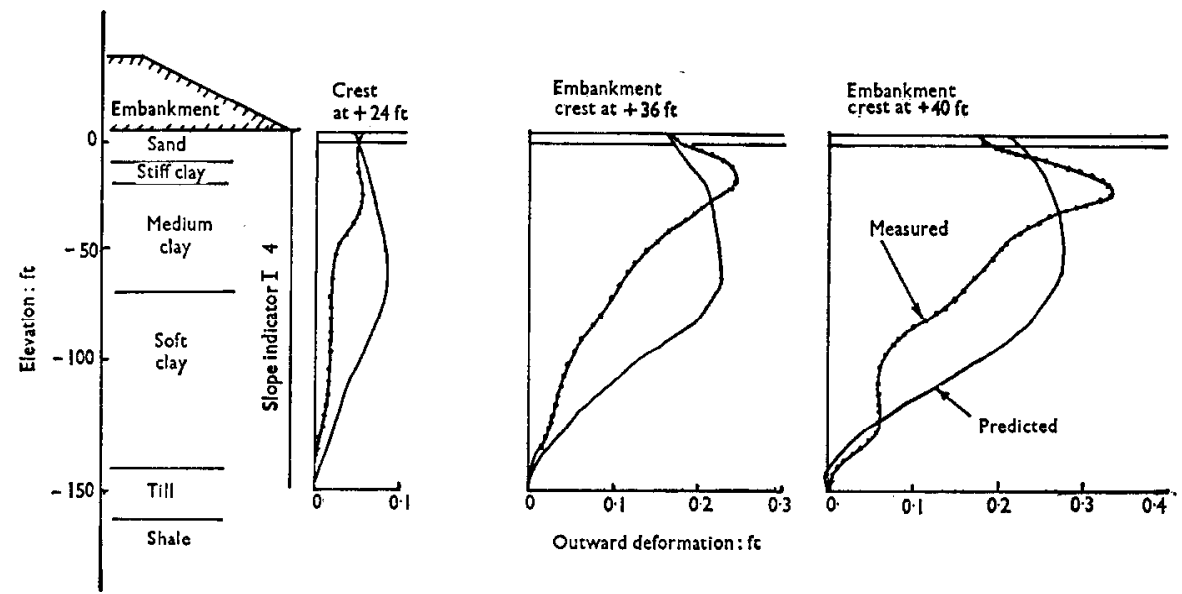

Fig. 25. Measured and predicted lateral deformations at toe of embankment
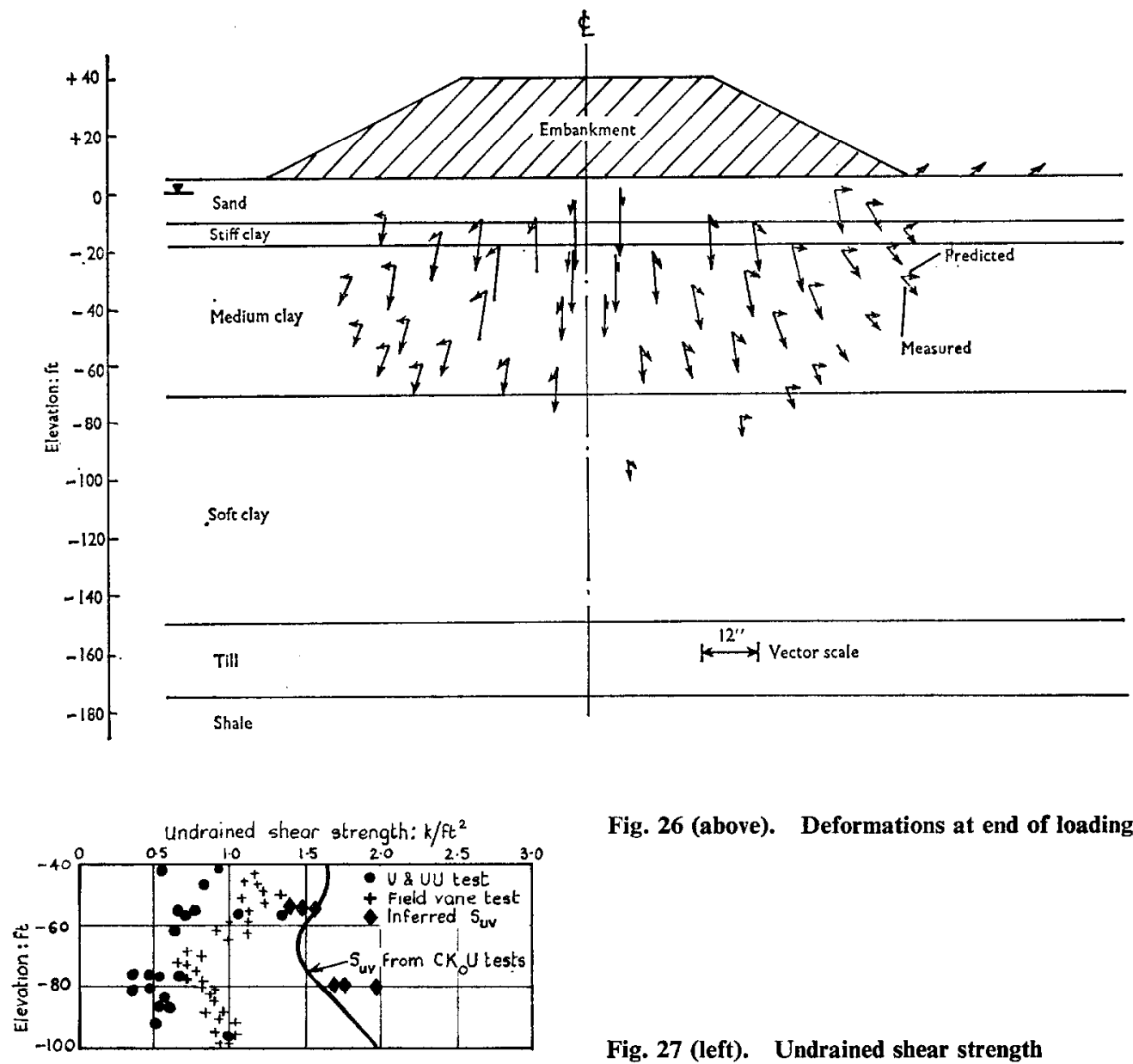

Fig. 26 (above). Deformations at end of loading 
from field pore pressure measurements. Table 11 shows factors of safety predicted by various techniques, using various strength data. As the embankment was safely carried to its design elevation of $+40 \mathrm{ft}$, any factor of safety lower than unity is incorrect. Since no failure occurred, however, no meaningful comparison can be made between predicted and actual factors of safety. A study of the various plots of field data led me to infer that the factor of safety, when the embankment had reached its full height, was probably between 1.3 and 1.5 .

\section{Discussion}

The huge quantity of field performance measurements at the MIT Test Section permits a detailed picture of deformations which occurred within the foundation under the embankment. The foundation did not move upwards or inwards as predicted by some of the techniques employed. In general, however, the magnitude and rate of settlement of the embankment was not very different from that predicted.

Two problems arise in evaluating predictions made at the MIT Test Section. First, since no measurements were made of total stress in the foundation, no meaningful evaluations could be made of techniques for predicting increments of total stress. Second, the large differences in shear strength values as determined by various methods present the engineer with a dilemma when making predictions of stability.

Table 11. Factors of safety from stability analysis (D'Appolonia et.al., 1971)

\begin{tabular}{c|c|c|c|c}
\hline \multirow{2}{*}{$\begin{array}{c}\text { Embankment } \\
\text { elevation, } \\
\mathrm{ft}\end{array}$} & $\begin{array}{c}\text { Effective stress } \\
\text { analysis }\end{array}$ & \multicolumn{3}{|c}{ Total stress analysis } \\
\cline { 2 - 5 } & $\mathrm{U}$ and UU & Vane & $\mathrm{CK}_{0} \mathrm{U}$ \\
\hline+24 & $1.65^{*}$ & 1.06 & $1.65^{*}$ & $1.65^{*}$ \\
+30 & $1.57^{*}$ & $\mathbf{0 . 8 7}$ & 1.40 & $1.57^{*}$ \\
+36 & 1.53 & $\mathbf{0 . 7 3}$ & 1.18 & 1.50 \\
\hline
\end{tabular}

* Critical failure surface does not pass into clay.

\section{LAGUNILLAS PRELOAD}

\section{Description}

At Lagunillas on the east coast of Lake Maracaibo, Venezuela, the Creole Petroleum Corporation had to construct three very heavily loaded tanks on weak subsoil. Analyses indicated that the tanks could not be constructed on the foundation as it existed, and furthermore, that preloading was the most economical solution to the problem. Fig. 28 shows the preload and subsoil along with some of the instrumentation in the foundation clay. The Lagunillas Preload case has been described (Lambe, 1962).

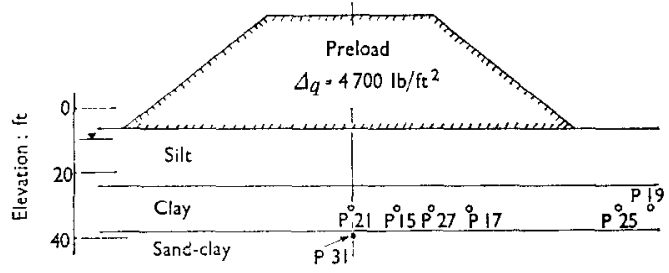

Fig. 28. Lagunillas Preload 


\section{Stresses}

Figure 29 shows the results of vane shear tests in the foundation clay before and at several times during consolidation of the foundation clay under the application of the preload. Fig. 30 presents pore pressure and settlement data, and Fig. 31 compares predicted and measured pore pressures in the foundation clay.

As indicated in Fig. 31 an extremely good prediction-a type A prediction-was made of the excess pore pressures generated in the clay, by the preload. The close agreement between predicted and measured pore pressures is particularly interesting in view of the fact that elastic theory was used in the prediction to obtain stress changes. As indicated in Table 12, elastic theory predicts shear stresses at the piezometer locations which are far in excess of the clay shear strength. They are, in fact, as large as 3.5 times the initial undrained shear strength. As indicated by Höeg et al. (1969) yield in the Lagunillas foundation clay began when about only one third of the preload had been placed.

\section{Deformations}

Figure 30 shows an accurate prediction (type A prediction) was made of initial settlement, consolidation settlement and rate of settlement. The initial settlement prediction was based on elastic theory using a modulus, $E_{\mathrm{u}}$, equal to $250 \mathrm{~s}_{\mathrm{u}}$. The value of $E_{\mathrm{u}}=250 \mathrm{~s}_{\mathrm{u}}$ was obtained from laboratory stress-strain data for a very large strain. Considerable judgement (and luck) was required in this apparently good choice of $E_{\mathrm{u}}$.

The magnitude and rate of consolidation settlement was predicted on the basis of $C_{\mathrm{c}}$ and $c_{\mathrm{v}}$ values obtained from oedometer tests. Double drainage in the clay was used in the prediction. To check the drainage condition at the bottom of the clay, P31 was installed. Apparently, full drainage did not exist.

\section{Stability}

Using a bearing capacity equation, $q_{\mathfrak{u}}=6 \cdot 2 s_{\mathrm{u}}$, with an average initial undrained shear strength of $500 \mathrm{lb} / \mathrm{ft}^{2}$ indicated a factor of safety, for the full preload and undrained condition in the foundation, of $0 \cdot 6$. This predicted factor of safety was deemed conservative. An unconservative upper limit of the factor was obtained using the method of slices employing drained strength in the preload pads and silt with initial undrained strength as indicated by the vane in the clay. This approach gave a predicted factor of safety of slightly less than unity, i.e. 0.9.

The predicted factors of safety indicated that it would be prudent to place the preload slowly enough to permit some consolidation of the foundation clay. As indicated in Fig. 30, this

Table 12. Shear stress at piezometers; shear strength of clay $400-500 \mathrm{Ib} / \mathrm{ft}^{2}$

\begin{tabular}{c|c}
\hline Piezometer & $\begin{array}{c}\left(\Delta \sigma_{1}-\Delta \sigma_{3}\right) / 2 \text { by elastic theory, } \\
\mathrm{lb} / \mathrm{ft}^{2}\end{array}$ \\
\hline P21 & 1220 \\
P15 & 1290 \\
P23 & 1360 \\
P27 & 1390 \\
P25 & 1460 \\
P19 & 330 \\
& 290 \\
\hline
\end{tabular}




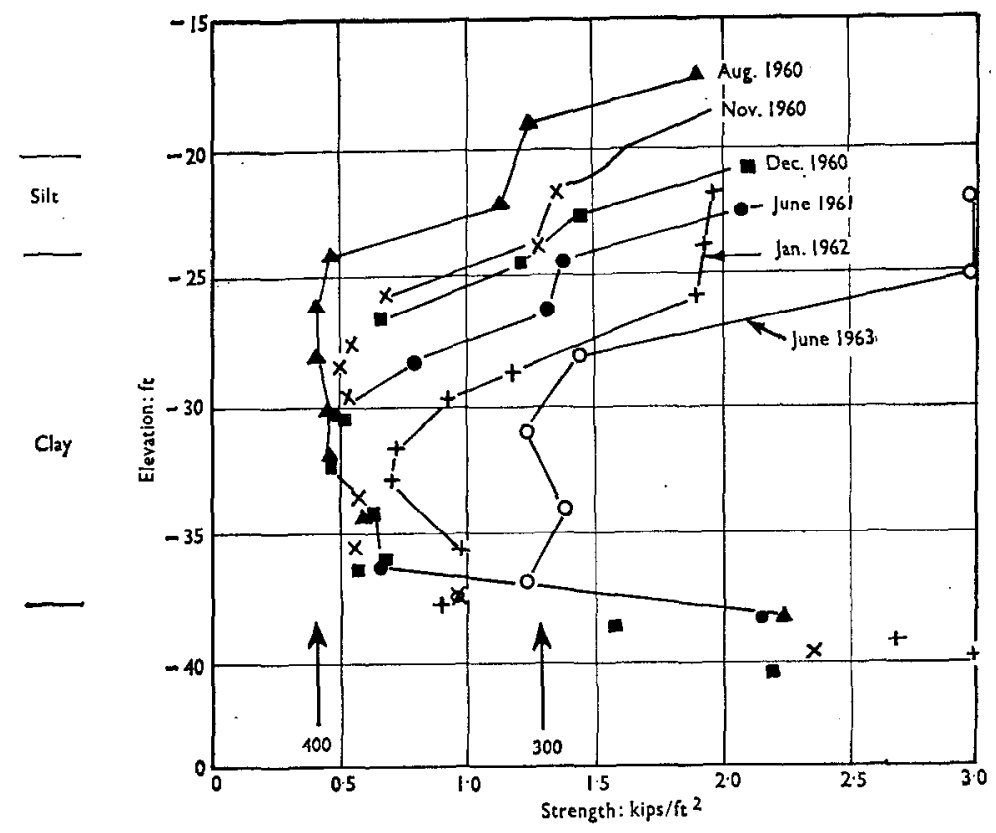

Fig. 29. Field vane shear strengths

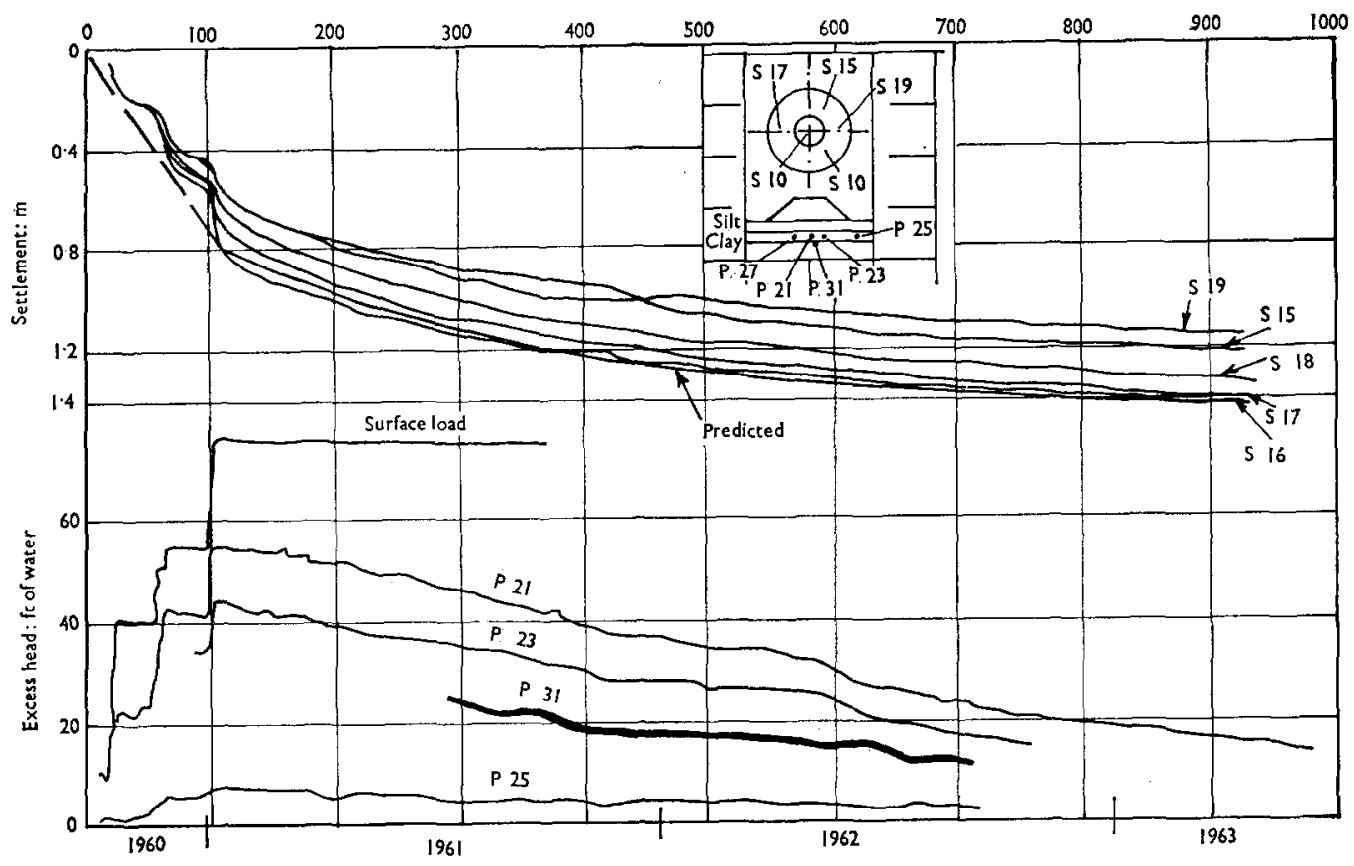

Fig. 30. Performance of preload 

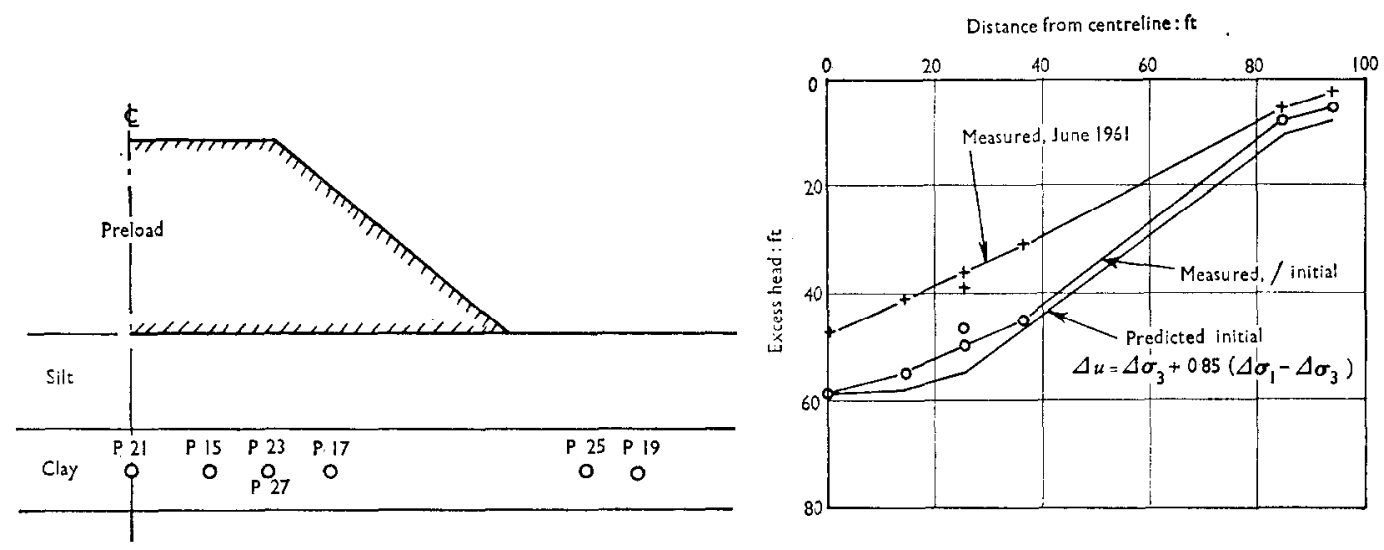

Fig. 31. Predicted and measured pore pressures

procedure was employed. As failure of the foundation under the preload did not occur and as an undrained loading under the full preload did not occur, no meaningful evaluation of the predicted factors of safety can be made.

\section{Discussion}

The Lagunillas Preload case demonstrates two very interesting facts. First, it is possible to make an exceedingly accurate prediction of excess pore pressures, using an inappropriate

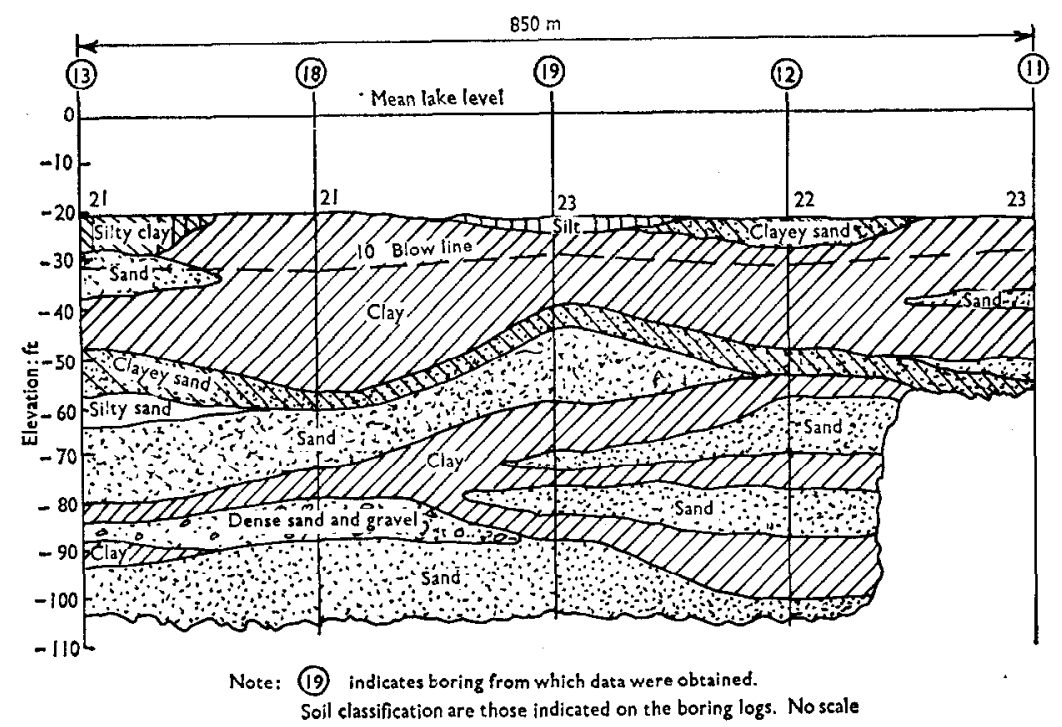

Fig. 32. Soil profile before filling 


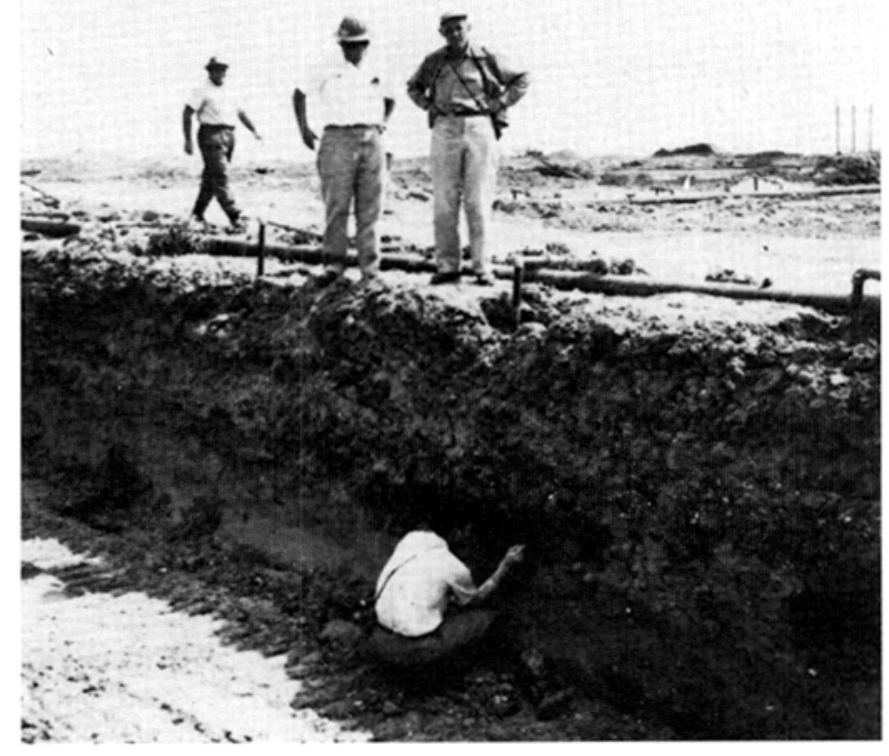

(b)

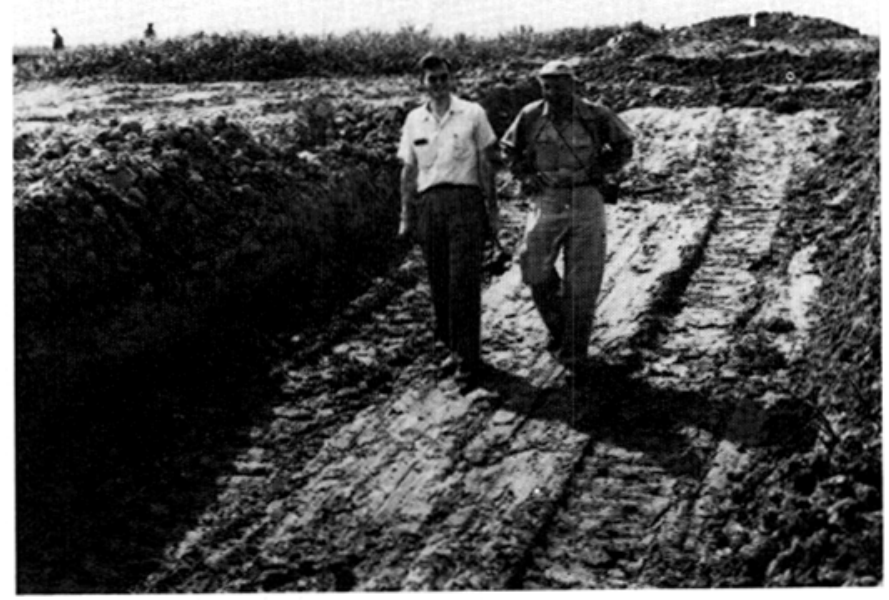

Fig. 33. Terzaghi and Peck examining placed fill 


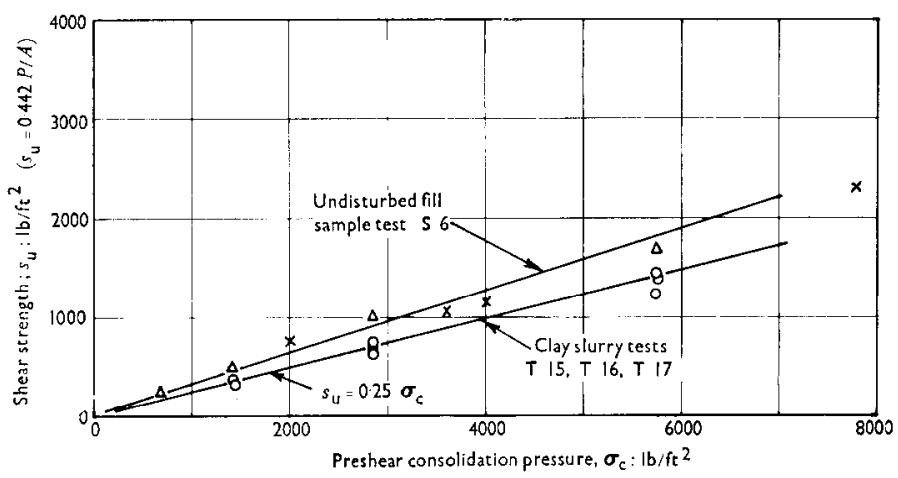

Fig. 34. Results of strength test on fill

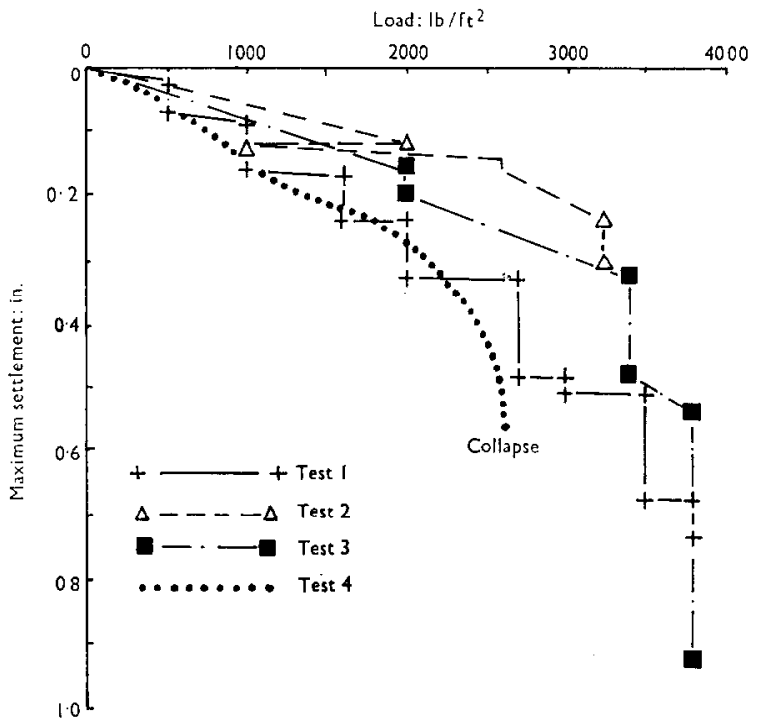

Fig. 35. Load-settlement curves

Table 13. Properties of fill, based on laboratory tests

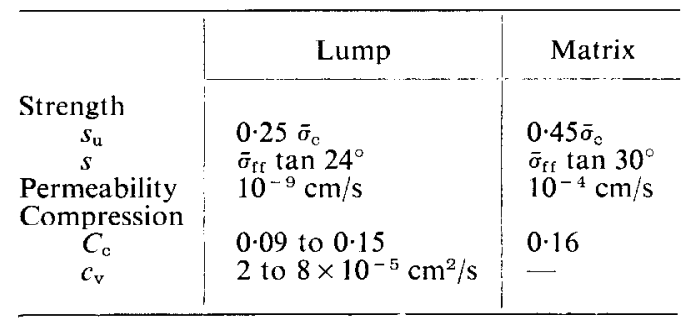


theory (elastic theory), and second, a very accurate prediction of settlement was made by use of an inappropriate theory (elastic theory), incorrect boundary conditions and soil parameters obtained from laboratory tests.

\section{LA SALINA LOAD TESTS}

\section{Description}

Dredging near the mouth of Lake Maracaibo, Venezuela, permitted large tankers to enter the lake in the 1950s. To handle these large tankers the Creole Petroleum Corporation had to construct a channel and a marine terminal facility. The high cost and general scarcity of shoreline, and a need to dispose of the soil dredged from the channel, led to the decision to build the terminal approximately $2200 \mathrm{ft}$ offshore from the industrial area of La Salina. The terminal was to contain facilities for the storage of petroleum products, the docking of tankers and the fuelling, deballasting and loading of tankers.

The Marine Terminal is rectangular $(850 \mathrm{~m}$ by $600 \mathrm{~m})$ and is enclosed by a wall of reinforced concrete piles. Hydraulic fill was placed within the enclosed area to raise the soil surface from the original elevation of approximately $-20 \mathrm{ft}$ to approximately $+6 \mathrm{ft}$. Fig. 32 shows the soil profile along the southwest wall of the terminal before the placement of hydraulic fill.

\section{Properties of fill}

As indicated in Fig. 32, the foundation soils at the Marine Terminal vary erratically as is typical of nearshore lake deposits. As suggested by Fig. 32 most of the material dredged from the channel consisted of clay. The hydraulic fill as it came from the dredge pipe on to the terminal consisted of lumps of stiff foundation clay, of diameters varying from 0.25 in. to 18 in. The voids among the clay lumps were filled with a matrix of fine sand and silt. The dredge discharge pipe built up large mounds of soil at the pipe exit with the size of clay lumps decreasing as one moved away from the exit of the discharge pipe.

In designing foundations for structures to be placed on the terminal, the soil engineer immediately faced the question of whether the soil deposited near the discharge pipes would behave like a stiff clay, like a sandy silt, or like a softened clay. Fig. 33 shows a bulldozer cut made in the hydraulic fill consisting of clay lumps and sandy silt matrix. Terzaghi and Peck (both were involved with this project during its early stages) are examining the fill. Laboratory tests were run on samples of clay lumps and on samples of sandy silt matrix. Table 13 and Fig. 34 show some of the results of these laboratory tests.

\section{Tank tests}

The engineers responsible for the La Salina Marine Terminal unanimously concluded that meaningful predictions of performance could not be made from soil parameters obtained solely by laboratory tests. Field load tests were designed and executed. In each test the load was applied by filling a steel tank with saturated soil. Four tests were conducted according to the schedule shown in Table 14.

Figures 35 and 36 show some of the results of the four tank load tests. Fig. 37 predicts the failure load for the most unfavourable possibilities of an undrained loading on softened clay material. As indicated by the results of the tank tests, the measured bearing capacity was 2 to 3 times this unfavourable prediction. 


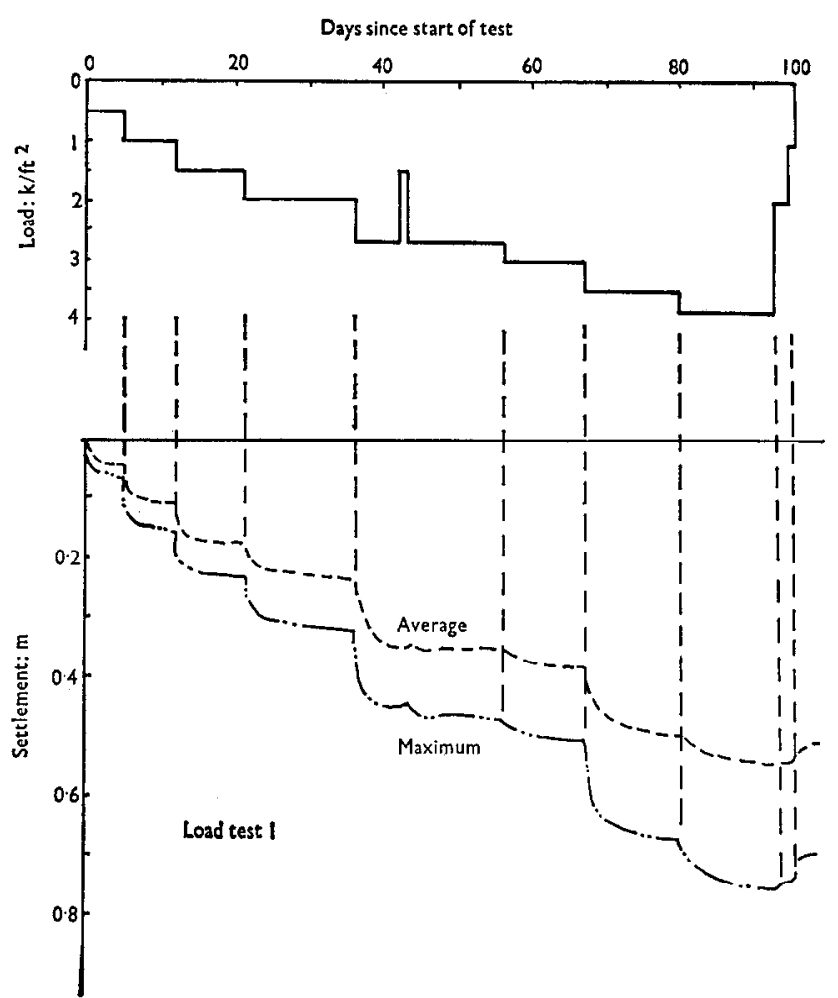

Fig. 36. Load test 1

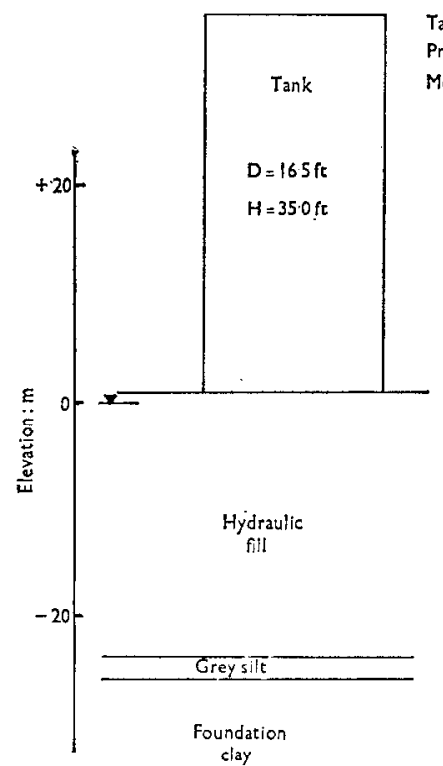

Tank failure

Predicted ; $q_{\mathrm{u}}=N_{\mathrm{c}} s_{\mathrm{u}}=6 \times 200=1200 \mathrm{lb} / \mathrm{ft}^{2}$

Measured; $T 3 q_{4}=3500 \mathrm{lb} / \mathrm{ft} 2$ $T 4 q_{\mathrm{u}}=2640 \mathrm{lb} / \mathrm{ft}^{2}$

$\stackrel{4}{4}$
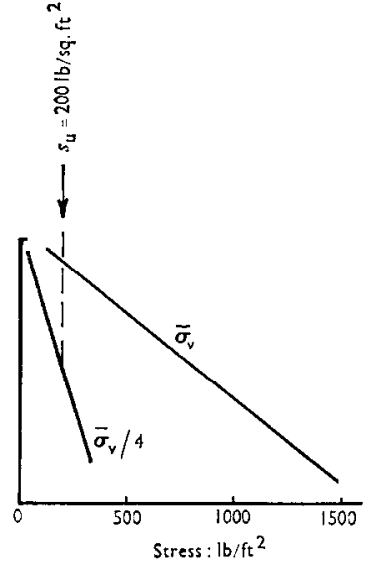

Fig. 37. Bearing capacity 
Table 14. Tank tests

\begin{tabular}{c|c|c|c|c}
\hline Test & Tank diameter, ft & Type of test & $\begin{array}{c}\text { Number of load } \\
\text { increments }\end{array}$ & $\begin{array}{c}\text { Time of complete } \\
\text { loading, d }\end{array}$ \\
\hline 1 & $21 \cdot 5$ & Slow & 8 & 80 \\
2 & $16 \cdot 5$ & Rapid & 2 & 2 \\
3 & $16 \cdot 5$ & Rapid & 3 & 3 \\
4 & $16 \cdot 5$ & Very rapid & 1 & 1 \\
\hline
\end{tabular}

The tank load tests permitted the development of semi-empirical predictive techniques for both stability and settlement. They permitted good predictions of settlement for the structures later built on the terminal. In general, the load tests indicated that the clay balls did not undergo extensive softening that would permit shear failures through weak clay material. Further, the tank load tests indicated that consolidation of the hydraulic fill would proceed very rapidly. For example, in Tank Test 1 approximately $90 \%$ consolidation occurred in the 80 day loading period. The test results suggest three-dimensional consolidation with an equivalent $c_{\mathrm{v}}$ of approximately $1 \mathrm{~cm}^{2} / \mathrm{s}$.

\section{Discussion}

The La Salina case has been presented for one reason: that is to indicate that situations exist in which laboratory soil tests alone are inadequate to permit meaningful predictions to be made. Although extensive laboratory tests were conducted these tests failed to indicate whether the fill consisting of stiff clay balls interspersed with sandy silt would behave as a stiff clay, sandy silt or a softened clay. The prediction techniques used for the design and construction of facilities on the terminal were based on soil parameters obtained from the field tests.

\section{KAWASAKI TANKS}

\section{Description}

The desperate shortage of land available in Japan for industrial development has necessitated extensive site construction by the reclamation of underwater areas. Fig. 38 shows the geological profile through a reclaimed area in Kawasaki City, near Tokyo. The properties of this site have been described (Lambe, 1969).

The thick foundation clay at the Kawasaki site is consolidating under the placement of the hydraulic fill and from the removal of water by pumping from the sand-gravel aquifer below clay III. Values of measured total head at the Kawasaki site are shown in Fig. 39.

\section{Deformations}

Accurate predictions of settlement and stability for structures placed at the Kawasaki site were very important. Predictions of settlement were needed in order to design drainage systems properly, and especially to prevent water from Tokyo Bay from flooding the site. Predictions of stability were needed in order to locate structures at an adequate distance behind the waterfront.

Figure 40 presents a comparison of predicted tank settlement (type A prediction) and measured settlement of three large tanks. Agreement between predicted settlement and measured settlements is shown. This close agreement is surprising in view of the uncertainty 


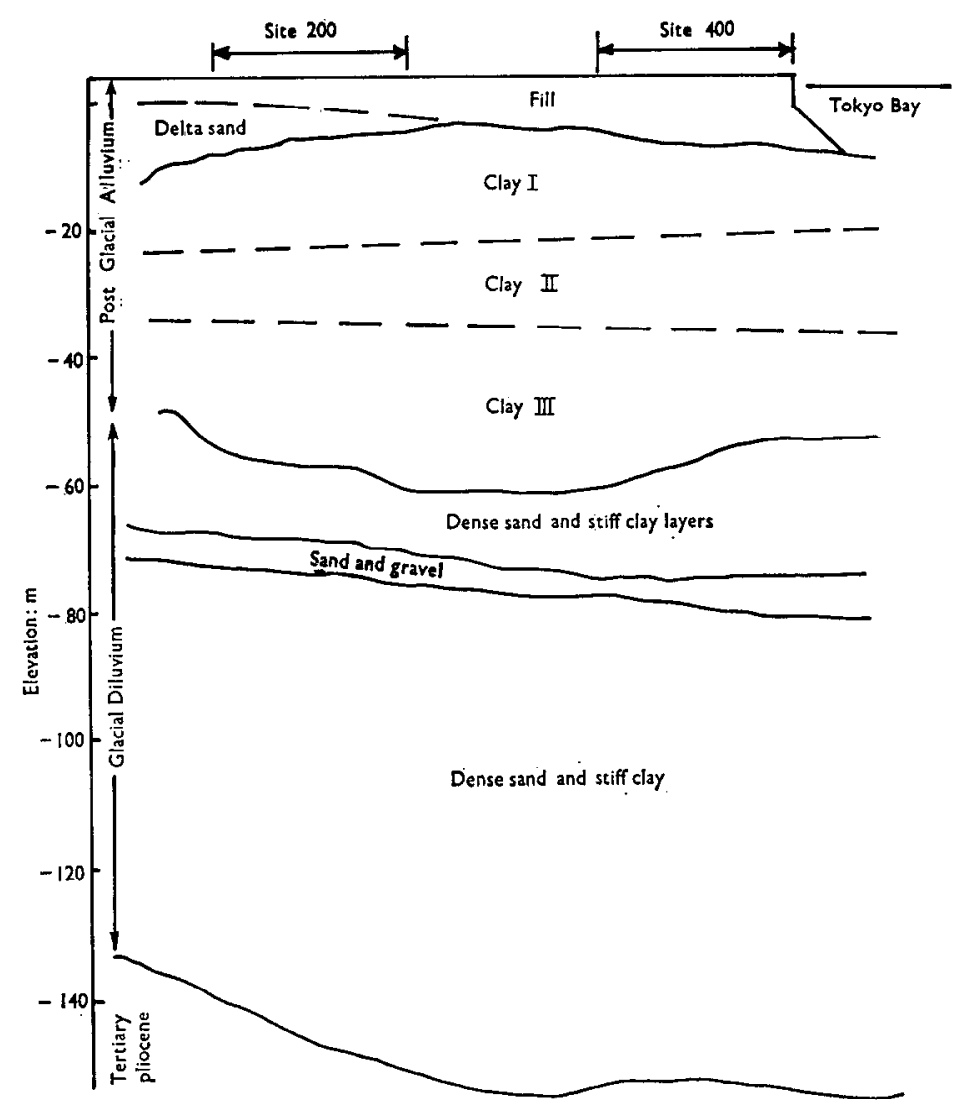

Fig. 38. Kawasaki soil profile

of the prediction, especially in the following aspects of method, soil parameters and loads. Both site and tank settlements were predicted on the basis of elastic theory and one-dimensional compression. Values of $c_{\mathrm{v}}$ measured on samples of undisturbed clay in oedometer tests varied from $1 \times 10^{-3}$ to $6 \times 10^{-3} \mathrm{~cm}^{2} / \mathrm{s}$. The three clay layers were transformed into one 'equivalent' clay layer having a value of $c_{\mathrm{v}}$ equal to $3 \times 10^{-3} \mathrm{~cm}^{2} / \mathrm{s}$. The prediction of tank settlement was based on the tank remaining full of oil. This loading was recommended by refinery engineers. A study of data on the in-service tanks indicated that using a full tank load was unreasonable. For example, over a ten month period one of the tanks experienced 20 load-unload cycles with the oil depth varying from $15 \mathrm{~m}$ to $1.9 \mathrm{~m}$, the time-average being about $7.5 \mathrm{~m}$.

These and other uncertainties were recognized when the settlement predictions were initially made. In fact, the engineer's report prepared at the time the predictions were made stated: 'No accurate estimates of settlement rates are thought possible until some additional data, especially field data, are available.' 


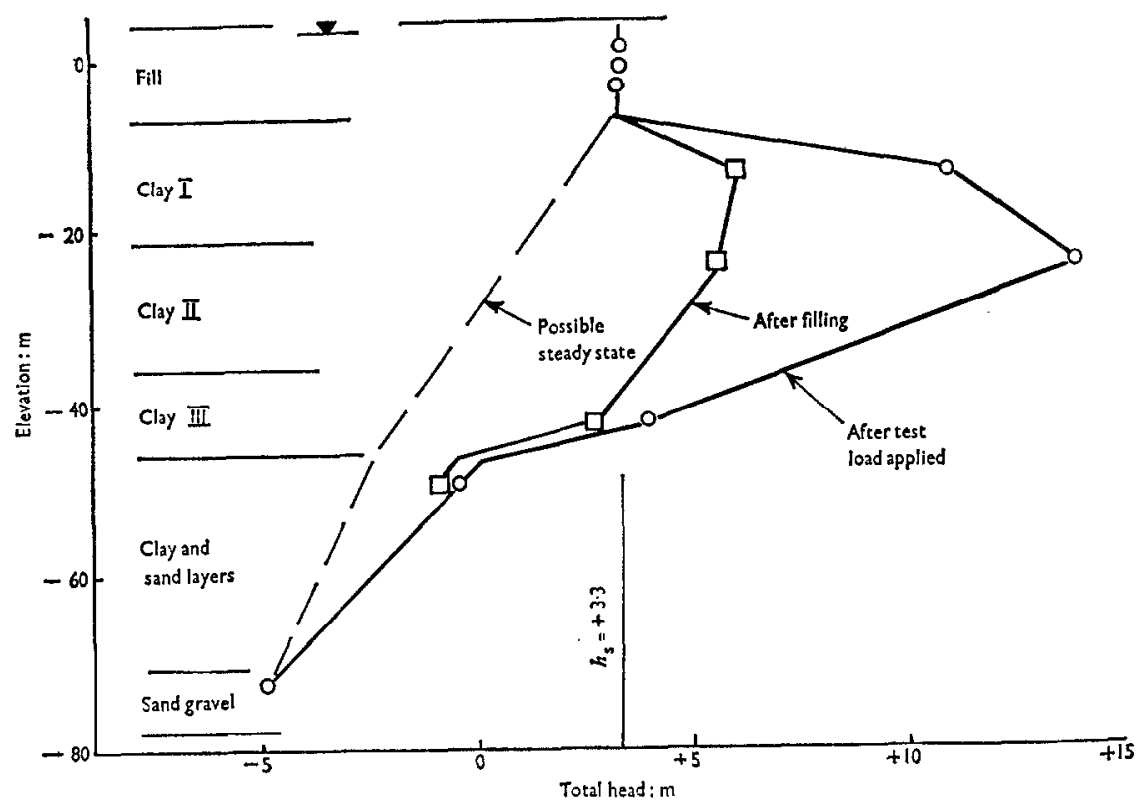

Fig. 39. Measured total head

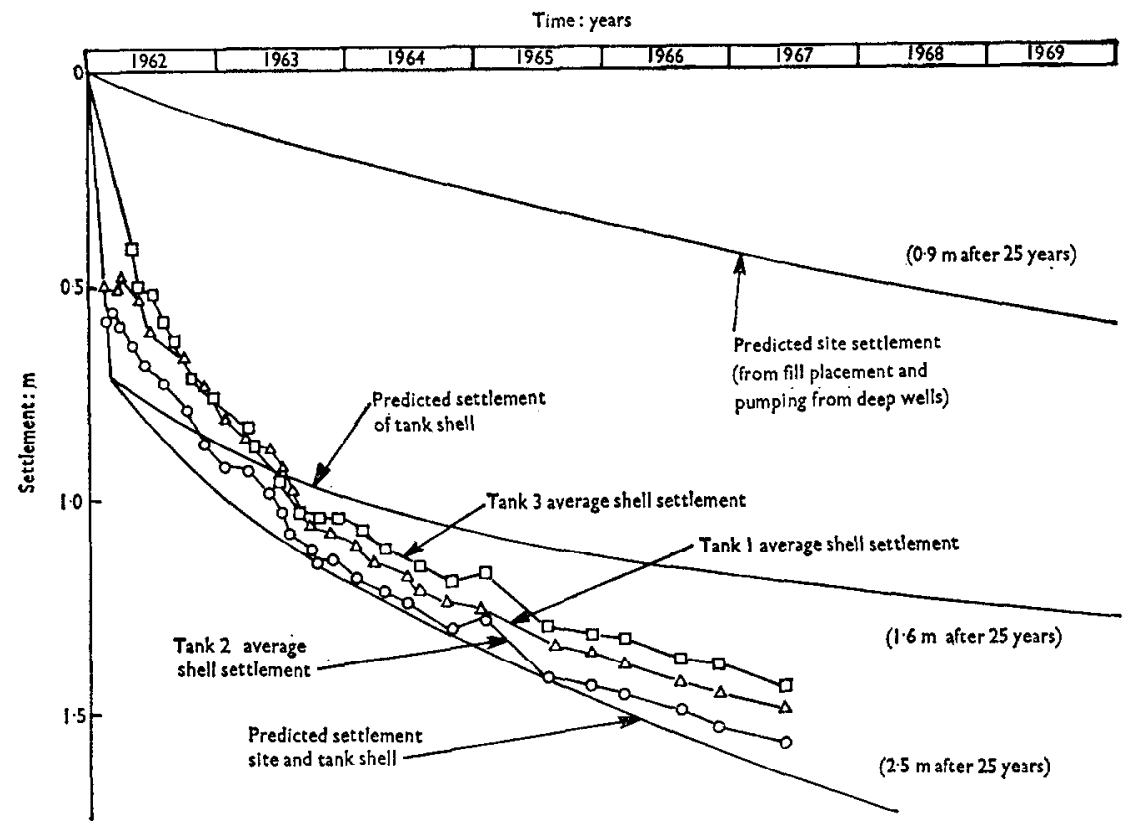

Fig. 40. Tank settlements 


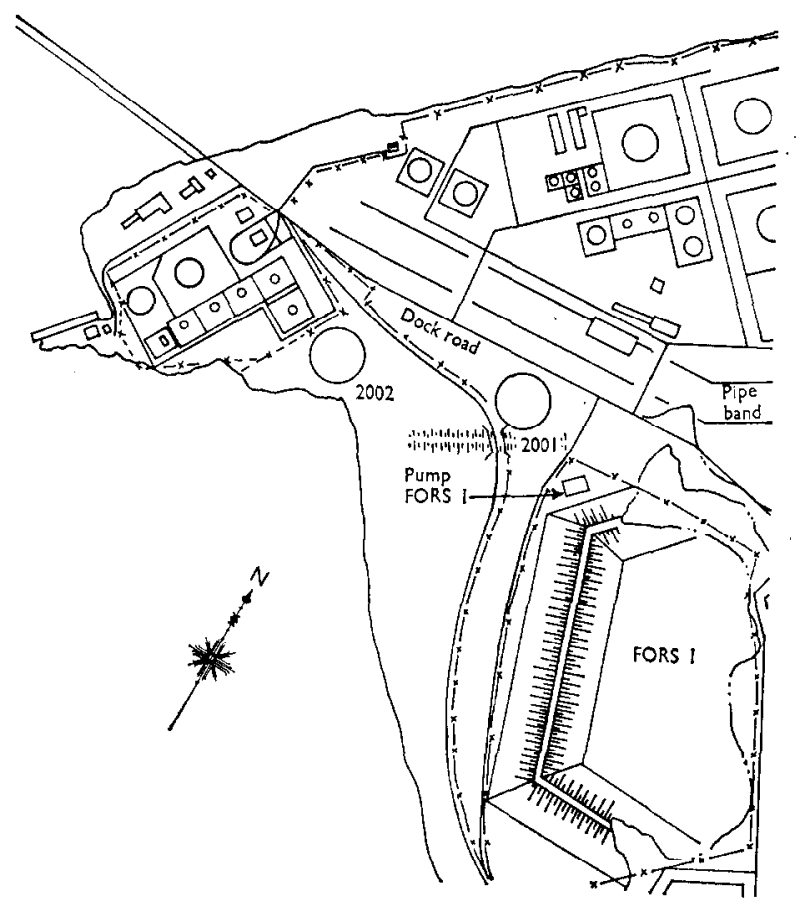

Fig. 41 (left). Plan of site

Fig. 42 (below). Preloads and soil profile

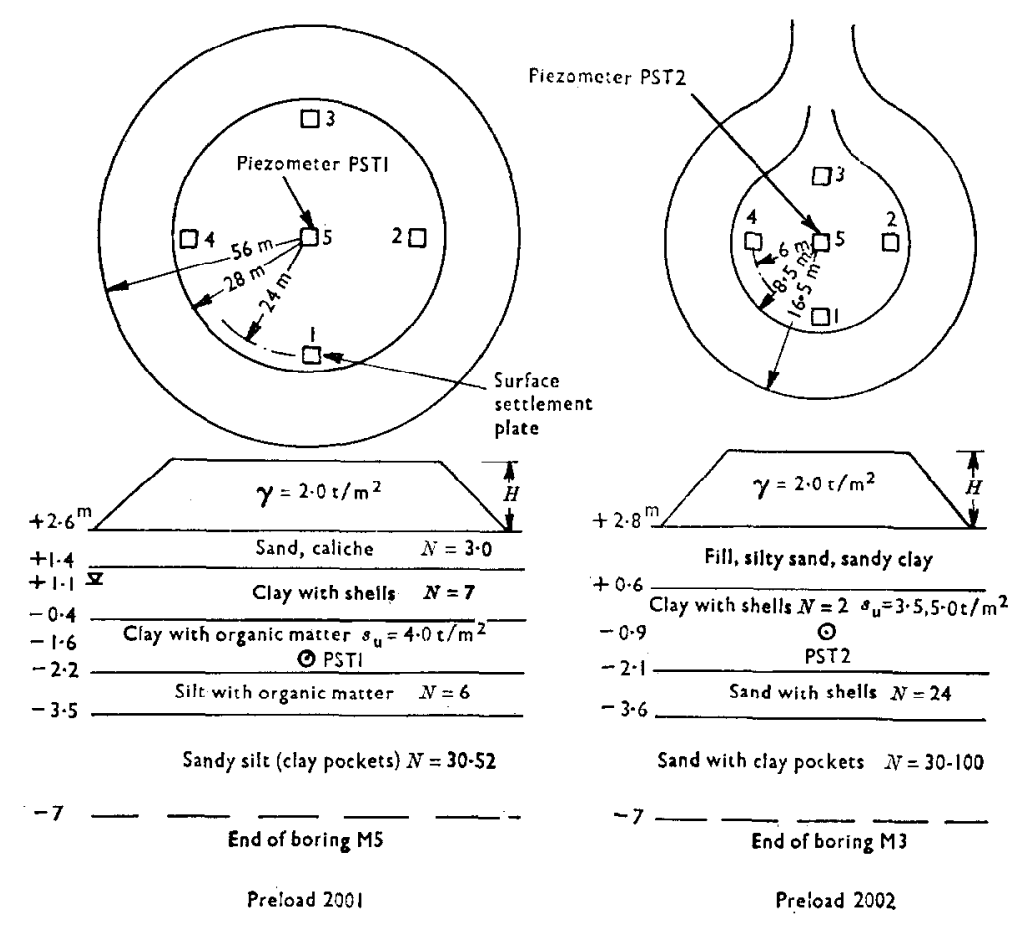




\section{Discussion}

The Kawasaki tank settlement case illustrates two important points. First, an accurate prediction of performance does not mean that the methods and data used to make the prediction are correct in all aspects, as a fortuitous cancellation of errors can result in an accurate prediction. Second, the engineer must not assume that a given site is in a static condition before construction. The Kawasaki site was settling due to fill placement and deep pumping, and knowledge of this fact was necessary in order to make appropriate settlement and stability analyses.

\section{AMUAY PRELOADS}

\section{Description}

The Creole Petroleum Corporation needed to erect two sulphur storage tanks as part of its desulphurization plant in Amuay, Venezuela. Fig. 41 locates the preloads and Fig. 42 shows plans and profiles of the two preloads.

Original plans called for the continuous placement of preload soil until the design height of $8 \mathrm{~m}$ had been reached. However, just prior to the beginning of preload placement, a nearby stockpile of clay caused a shear failure through the foundation when the stockpile had reached a height of $7 \mathrm{~m}$. In view of this foundation failure, field measuring devices were installed at the preload sites to permit a controlled rate of preload placement. Figs 43 and 44 present measurements from the instrumentation.

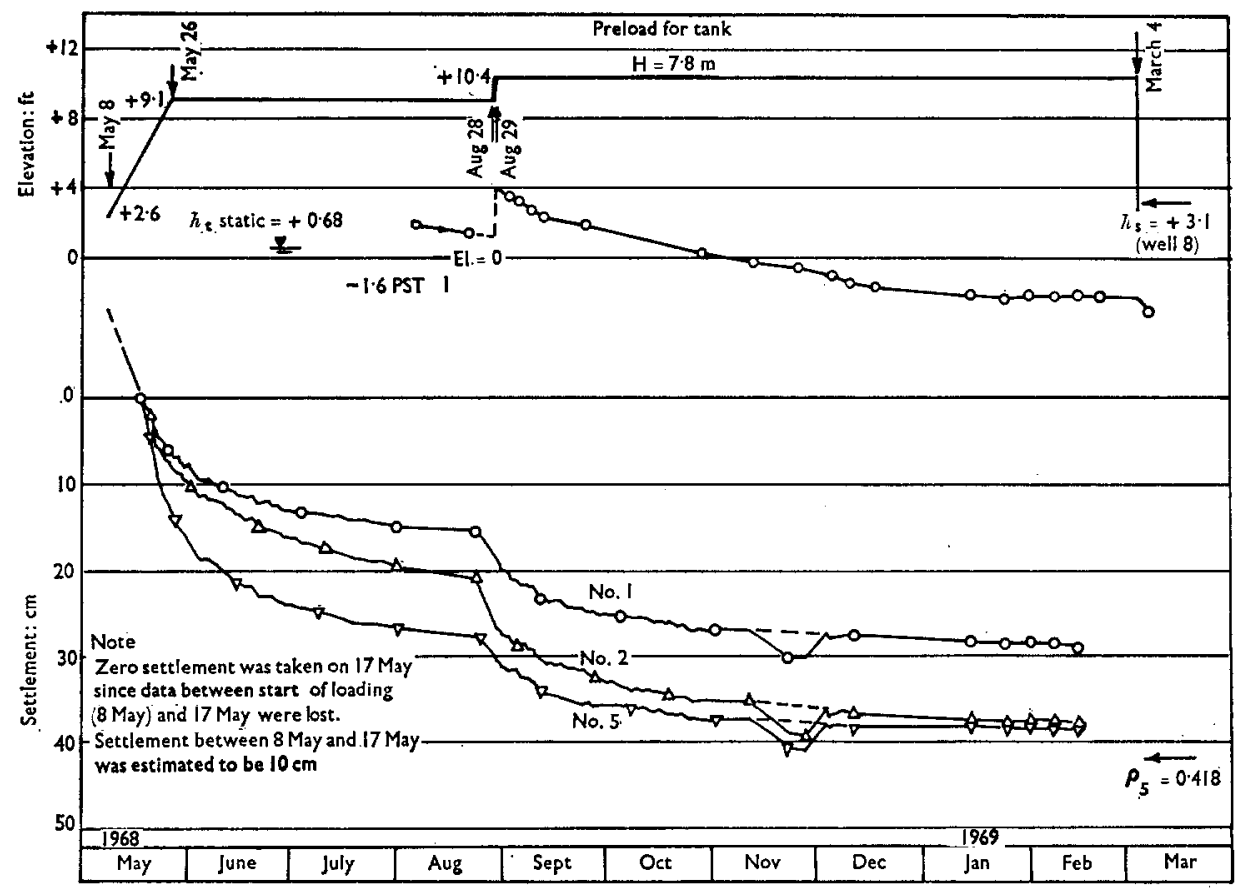

Fig. 43. Performance of preload 2001 


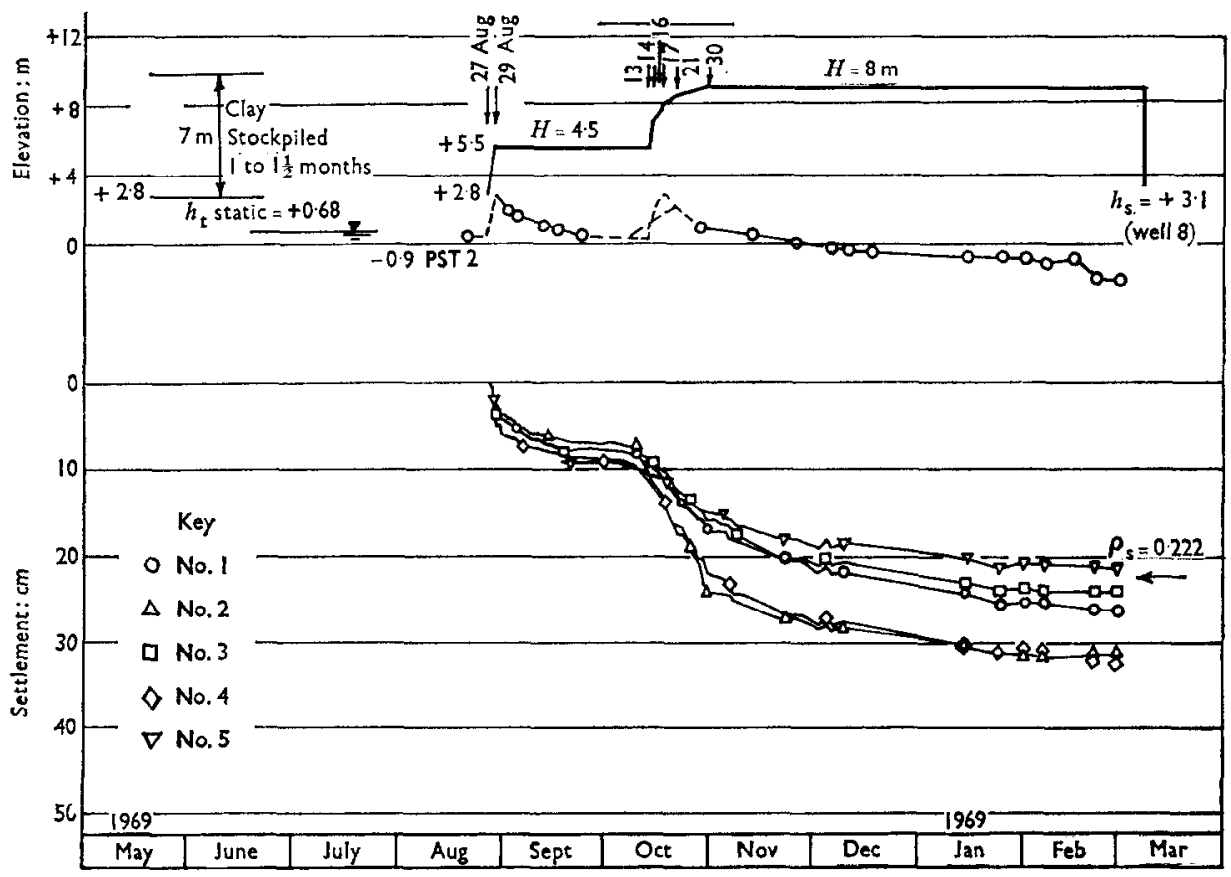

Fig. 44. Performance of preload 2002

\section{Stresses}

Figures 43 and 44 show that the two vibrating wire piezometers did not perform satisfactorily. Both piezometers indicated values of total head less than static head!

\section{Deformations}

Settlement measurements from the two preload sites are shown in Figs 43 and 44 and summarized in Table 15. As indicated in Table 15 the predicted values of initial settlement appear to be quite close to those which actually occurred. This is not at all surprising in view of the fact that the undrained modulus $\left(250 s_{\mathrm{v}}\right)$ used to make the 'predictions' of initial settlement was obtained from measured performance at a nearby oil storage reservoir.

The measured values of preload settlement indicate a variation among the different observation plates as large as $\pm 25 \%$ of the mean settlement.

Table 15. Amuay preloads

\begin{tabular}{c|c|c|c|c|c}
\hline Preload & $\begin{array}{c}\text { Diameter, } \\
\mathrm{m}\end{array}$ & $\begin{array}{c}\text { Load, } \\
\mathrm{t} / \mathrm{m}^{2}\end{array}$ & \multicolumn{3}{|c}{ Settlement, cm } \\
\cline { 3 - 6 } & & & $\begin{array}{c}\text { Predicted } \\
\text { initial }\end{array}$ & $\begin{array}{c}\text { Measured during } \\
\text { loading }\end{array}$ & $\begin{array}{c}\text { Measured at } \\
6 \text { months }\end{array}$ \\
\hline 2001 & 36.0 & 15.6 & 24 & $20-27$ & $34-46$ \\
$6-14$ & 10 & 16.0 & 16.5 & 10 & $21-33$ \\
\hline
\end{tabular}




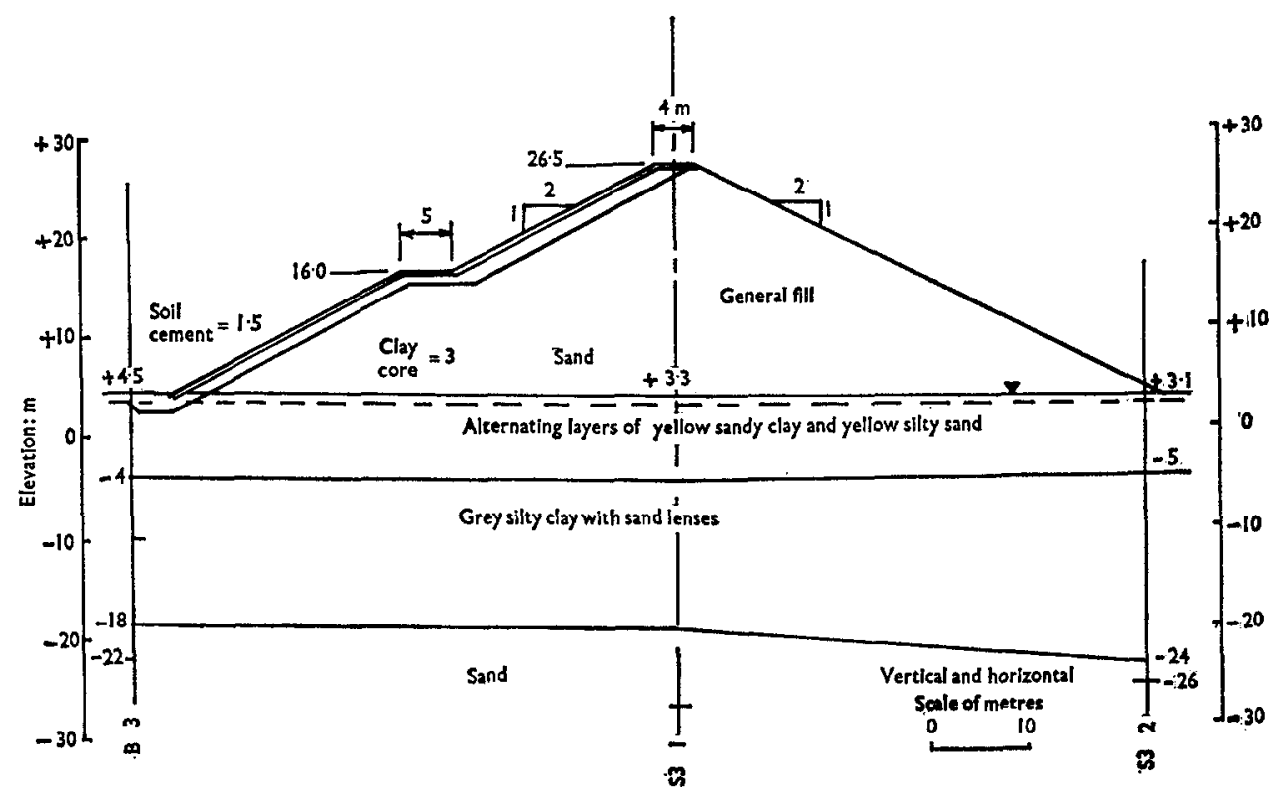

Fig. 45. Transverse section of FORS-3

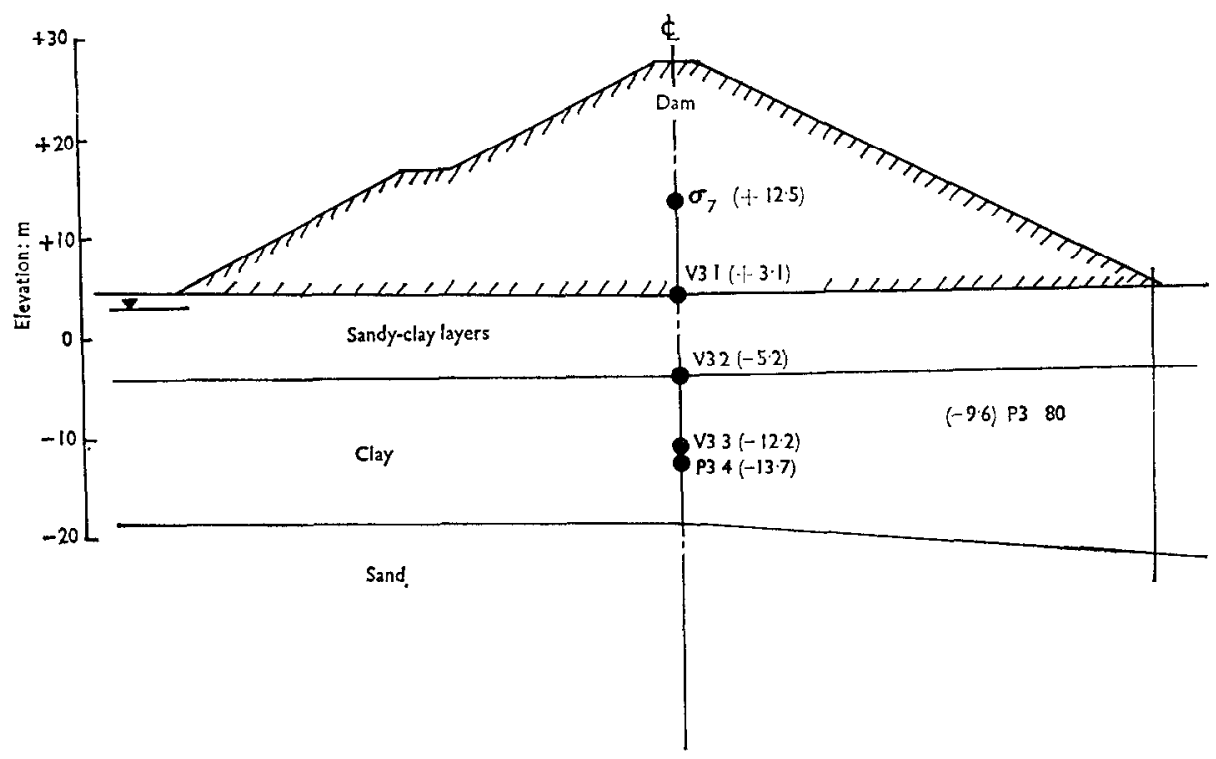

Fig. 46. FORS-3 instruments 


\section{Stability}

Consolidated-undrained triaxial tests on the soft clay under the preloads gave $s_{\mathrm{u}}=2 \cdot 5+$ $\bar{\sigma}_{\mathrm{v} 0} / 4$, resulting in a minimum shear strength at the top of the clay equal to $3.4 \mathrm{t} / \mathrm{m}^{2}$. The minimum shear strength recorded by the field vane was $3.5 \mathrm{t} / \mathrm{m}^{2}$. Because of the limited thickness of soft clay in the subsoil, one would expect the average undrained strength resisting a shear failure to be greater than $3.4 \mathrm{t} / \mathrm{m}^{2}$.

Using the expression bearing capacity $=5.7 s_{\mathrm{u}}$, a minimum bearing capacity of $19.4 \mathrm{t} / \mathrm{m}^{2}$ is given. However, the $7 \mathrm{~m}$ stockpile of clay (unit weight of $2 \mathrm{t} / \mathrm{m}^{3}$ ) caused a deep foundation failure even though the applied surface load was only $14 \mathrm{t} / \mathrm{m}^{2}$. If one accepts the expression for bearing capacity of $5.7 \mathrm{~s}_{\mathrm{u}}$, an average shear strength of $2.5 \mathrm{t} / \mathrm{m}^{2}$ is inferred.

\section{Discussion}

The Amuay Preloads case illustrates three interesting facts as follows.

First, even under favourable conditions, it may be difficult to get correct data from field instrumentation, especially electronic devices.

Second, the variation in measured performance may be large, even for relatively simple situations (settlement at various locations under the preloads apparently varied as much as $\pm 25 \%$ of the mean). Finally, an unexpected shear failure at the edge of a preload may occur. (Parry and McLeod, 1967, report a similar unexpected failure of an earth slope.)

\section{OIL STORAGE DAM}

\section{Description}

In 1955 the Creole Petroleum Corporation built its first fuel oil storage reservoir, FORS-1, and in 1956 its second, FORS-2. In 1962 FORS-1 was expanded from its original volume of 4 million barrels $\left(1\right.$ barrel $\left.=0.159 \mathrm{~m}^{3}\right)$ to 11 million barrels by raising the height of the dam from $13 \mathrm{~m}$ to $24 \mathrm{~m}$. The third Amuay fuel oil storage reservoir, FORS-3, was built during the period 11 April, 1969 to 19 August, 1969. This reservoir was formed by constructing a dam, $230 \mathrm{~m}$ long and $22.3 \mathrm{~m}$ high at its maximum height, to enclose a natural quebrada. FORS-3
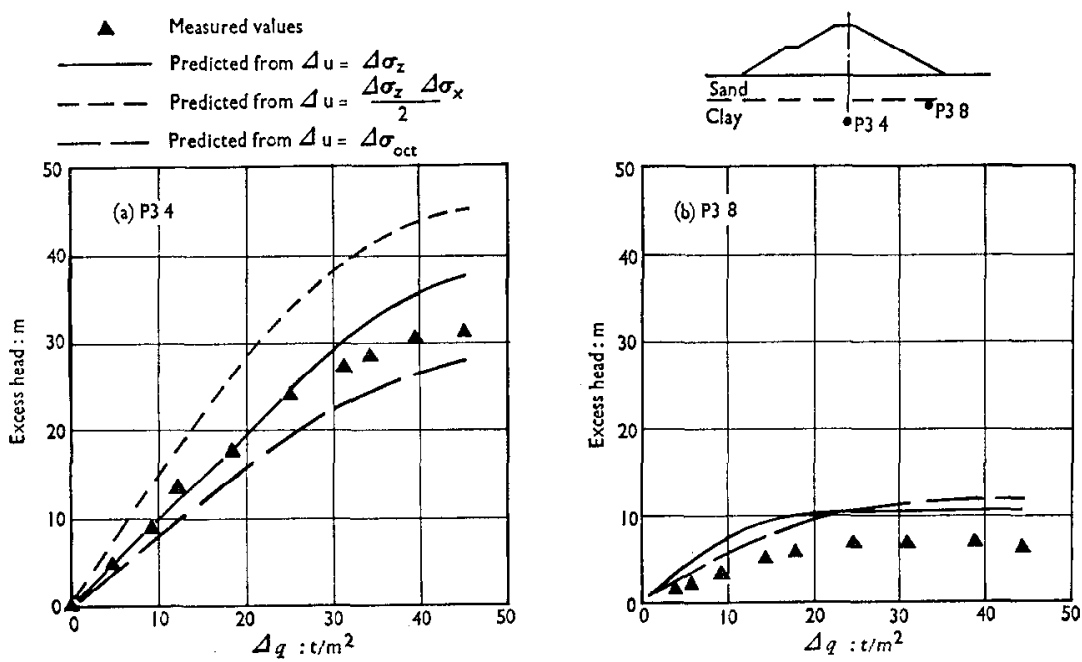

Fig. 47. Measured and predicted excess heads 

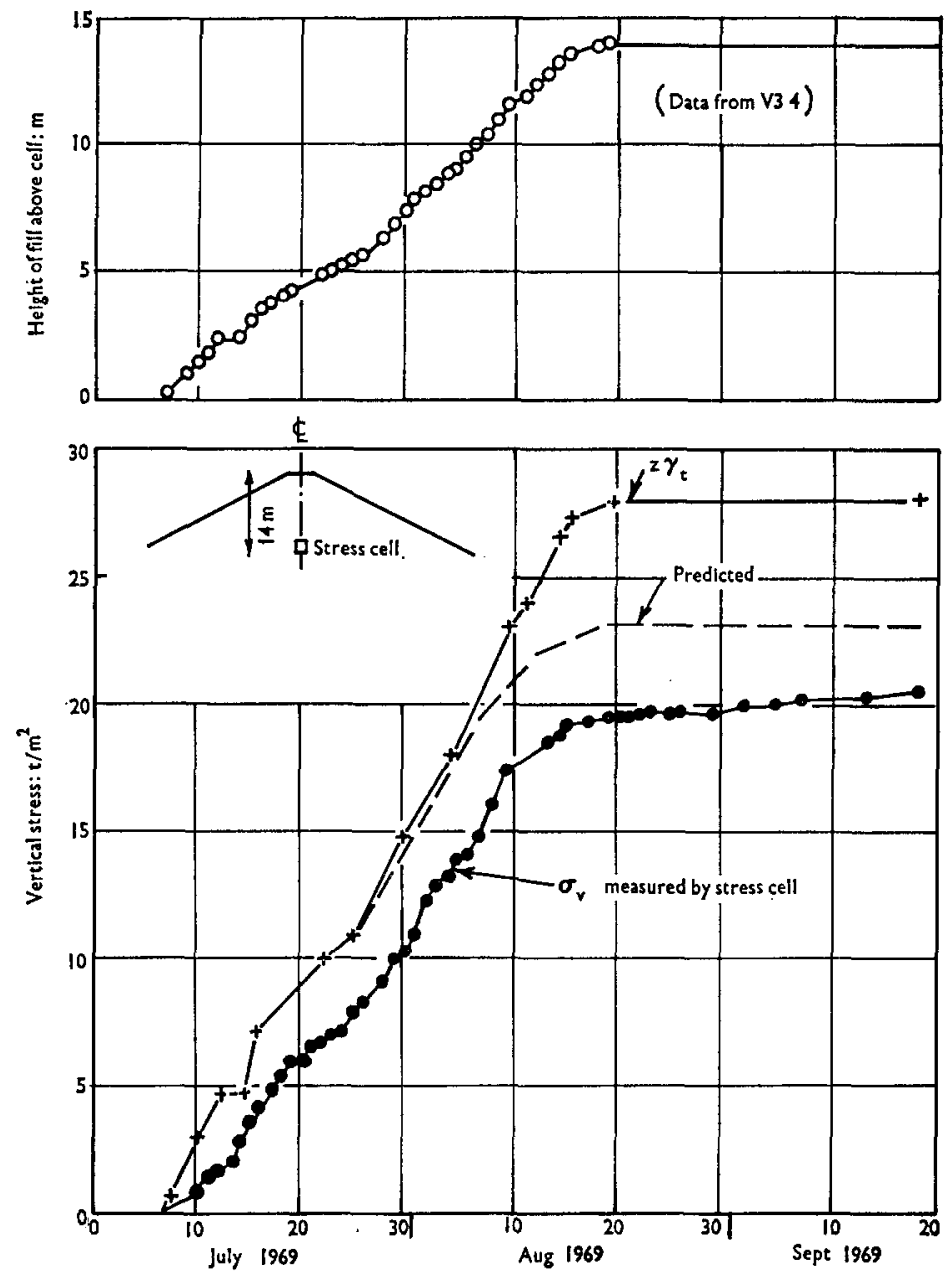

Fig. 48. Vertical stress in dam

has a capacity of 8 million barrels. Fig. 45 shows a cross-section through the earth dam.

The dam, foundation and adjacent hillside were instrumented with devices to measure deformations, pore pressures and strains. Fig. 46 locates some of the instruments.

\section{Stresses}

Figure 47 compares predicted (type A prediction) and measured excess total heads. These predicted heads agree well with the measured values. Fig. 48 compares predicted (type $\Lambda$ prediction) and measured total vertical stress measured in the dam by total stress cell $\sigma_{7}$. The predicted vertical stress was obtained using elastic theory and soil parameters from laboratory tests. As can be seen the measured vertical stress is always less than the overburden stress, being approximately $70 \%$ of it. The measured vertical stress increased slightly after construction was completed. 


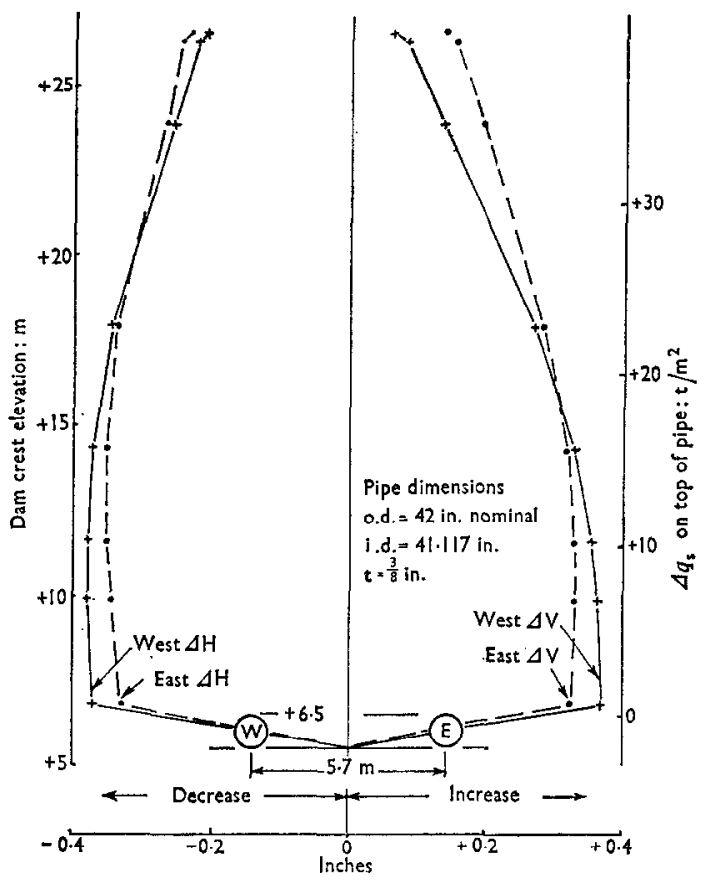

Fig. 49. Pipe diameter change

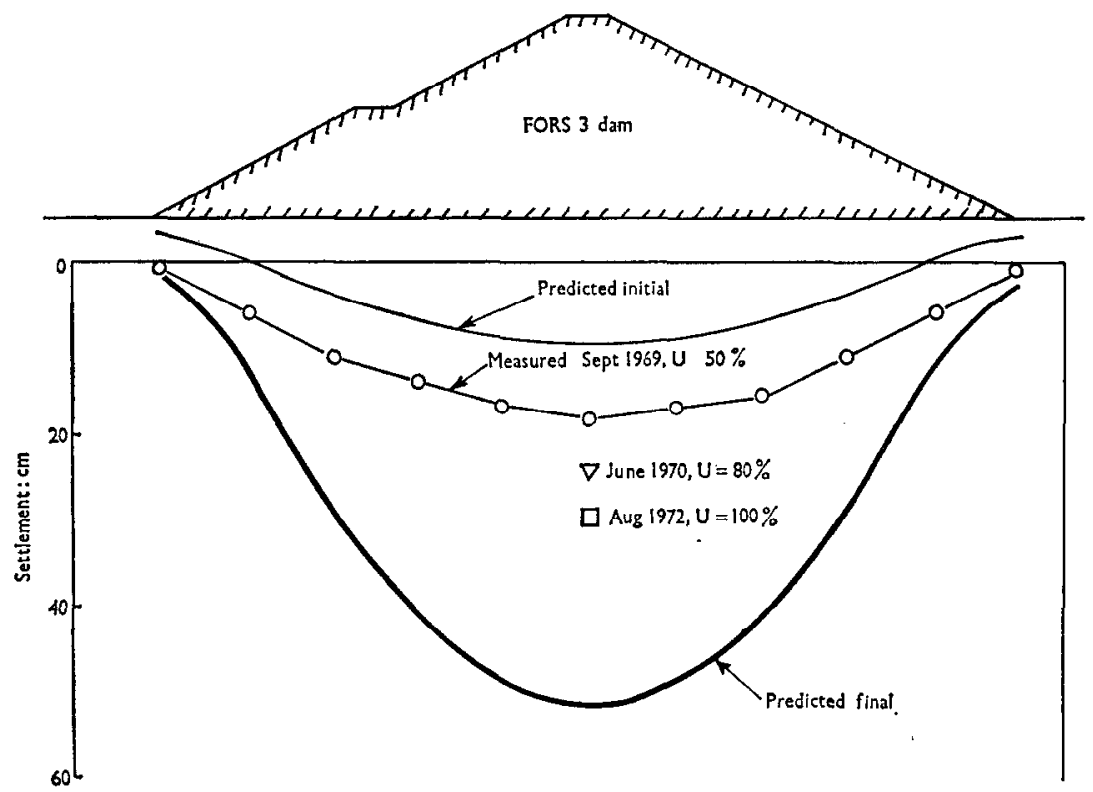

Fig. 50. Settlement of dam base 


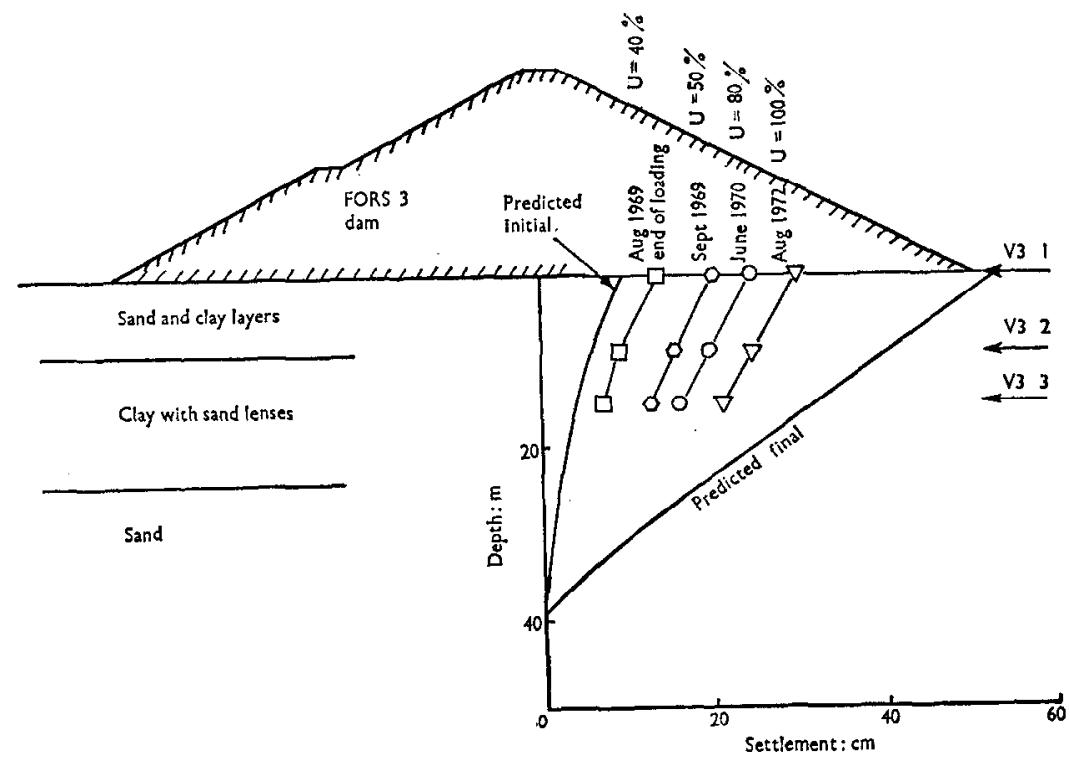

Fig. 51. Settlement of dam foundation

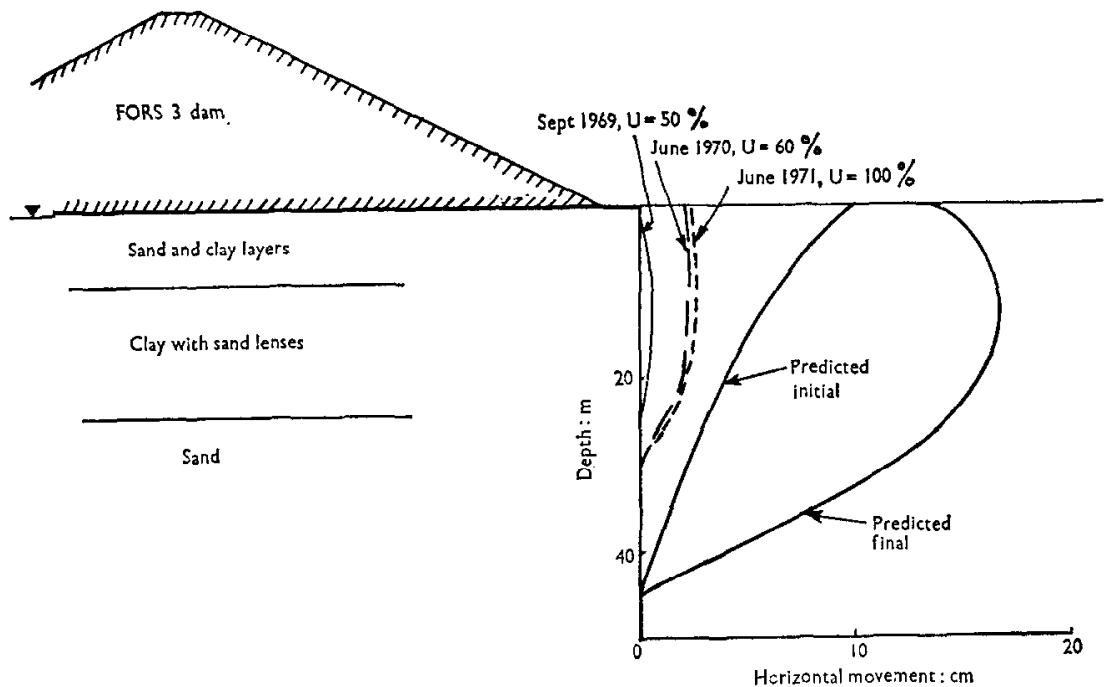

Fig. 52. Horizontal deformation at dam toe 


\section{Pipe deformation}

Oil is withdrawn from the storage reservoir through two large (42 in. diameter) suction pipes which pass under the base of the dam at elevation $+6.5 \mathrm{ft}$ (top of pipe). Fig. 49 shows measured changes in diameters of the two pipes as a function of dam crest elevation. Compaction of the soil at the sides of the two pipes during installation caused each to undergo an initial decrease in horizontal diameter of about $0.35 \mathrm{in}$. and a corresponding increase in vertical diameter. As construction proceeded, the horizontal diameter increased and the vertical diameter decreased, as would be expected. At the end of construction, an overall decrease of about 0.2 inches in horizontal diameter and an increase of 0.1 inches in vertical diameter had occurred.

Reliable techniques for predicting deformations of structures embedded in soil obviously depend on the selection of soil modulus. Experience with embedded pipes in other oil storage reservoirs at Amuay had indicated that careful control of soil compaction (high level of compaction along the sides of a pipe and less dense compaction on the top of the pipe) could significantly limit pipe deformations. Predictions made before the construction of FORS-3 indicated that approximately zero net change in pipe diameter could be obtained by construction control. As indicated in Fig. 49, the initial diameter changes effected by the dense lateral soil compaction were never overcome by the increased weight of overburden.

\section{Deformations}

Figures 50-52 show predicted and measured deformations. The predicted vertical and lateral deformations were obtained using DAMBUILD, a finite element computer program based on an ideal elastic isotropic embankment constructed on an ideal elastic isotropic foundation. Construction of the embankment was simulated by adding layers of elements to the original elements. A different program, FEAST-3, was employed to investigate the extent of local yielding within the foundation. FEAST-3 is a finite element program that allows for an initial anisotropic state of stress and for an elastic-plastic behaviour of the foundation. The FEAST-3 analysis indicated that very little plastic yielding would occur in the foundation and thus that the deformations predicted by DAMBUILD should not be grossly incorrect because of plastic yielding.

The predictions of deformation were made before the start of FORS-3 construction and thus are type A predictions. The soil parameters for the predictions were based on laboratory tests tempered by evaluated experience at Amuay. In particular, parameters were obtained from laboratory tests and then these parameters and DAMBuILD were employed to predict the known performance of FORS-1. The result of this comparison considered with empirical correlations of stress-strain moduli with strength, from other projects, influenced the selection of soil parameters.

Figures 50 and 51 indicate an accurate prediction of initial settlement. The comparison indicates an overprediction of consolidation settlement, especially in the near surface soil layers.

The consolidations expressed as percentages in Figs 51 and 52 are estimated from pore pressure readings at piezometer P3-4 located under the centreline of the embankment at mid depth of the clay layer, i.e. at elevation $-13 \cdot 7 \mathrm{~m}$.

As indicated in Fig. 52 predictions of lateral deformation at the toe of the embankment proved to be very inaccurate. Both initial and final predicted lateral deformations were much larger than the corresponding measured values, and the shape of the measured horizontal movement-the depth plot-is unlike that predicted, especially for initial movement. 


\section{Discussion}

The main lesson learned from the FORS-3 case is that evaluated experience in an area can greatly assist the engineer in making predictions of facilities constructed in that area. Predictions of excess pore pressure, pipe deformation and settlement at the FORS-3 dam were good. However, predictions of lateral deformation were poor. At the time predictions for FORS-3 were made there was good evaluated experience for pore pressure, pipe deformation and settlement but little evaluated experience on lateral deformations.

\section{EVALUATION OF PREDICTIONS}

\section{Nature and importance}

An evaluation of a prediction consists of an examination and interpretation of the prediction in the light of the known outcome of the predicted event. An evaluation of a prediction of structure performance is, therefore, built round a comparison of the predicted performance with the measured performance.

The evaluation of a prediction can be extremely important for both the welfare of the project at hand and the improvement of knowledge. The engineer on an actual project should evaluate those predictions critical to the project in order to make necessary changes in the design and/or construction method. For example, if the engineer on an important braced excavation job predicts strut loads of 200 kips but finds that the actual strut loads are going to be far in excess of $200 \mathrm{kips}$, he needs to re-examine his design and planned construction procedures. He then makes decisions and takes actions on the basis of his re-examinations. The Terzaghi-Peck 'Obervational Method' (Peck, 1969) depends on an evaluation of predictions.

I started preparation for this Rankine Lecture with the firm belief, essentially an a priori belief, that the evaluations of predictions constituted one of the most effective ways (if not, the most effective way) to advance the knowledge of our profession. My work reinforces this belief; however, several aspects of my reasons for this belief have altered. The remaining portion of this chapter presents some of my beliefs, based on the review of many field cases but especially those presented in this Lecture.

\section{Measured performance}

Terzaghi (1936) has stated: 'Our theories will be superseded by better ones, but the results of conscientious observations in the field will remain as a permanent asset of inestimable value to our profession' and 'Foremost among the urgent investigations ranks the painstaking observation of full-sized structures the world over, and the comparison between the observed facts with what was predicted from the results of soil investigations'. I firmly believe that the views Terzaghi held in 1936 are applicable today. In fact, the urgency of such investigations has increased.

The publication of a field case constitutes a significant contribution to our profession if the presented case contains enough performance and soil data to indicate what really happened. Publication merely of gross settlement with respect to time, for example, can be of little or no value. However, the publication of measured performance indicating the magnitude and direction of deformations at numerous locations in the foundation, can in fact be of "inestimable value'. Full presentation of the measured performance of the MIT Test Section could be of 'inestimable value'. 
Obtaining accurate measurements of structure performance is not as simple as the uninitiated might imagine. There are many difficulties, not the least of which is the unreliability of some field instrumentation. The unreliability of field instrumentation hindered several of the cases described in this Lecture, e.g. the Amuay Preload case in which difficulty was encountered in measuring pore pressure, one of the simplest geotechnical measurements.

In the cases I have described the loads applied to the foundations were known with a relatively high degree of certainty. In practice, this is not the usual case. Cases involving buildings, live loads and so on are especially difficult to interpret because one seldom knows the magnitude, to say nothing of the distribution, of the load applied to the subsoil.

Our profession has done a relatively good job in measuring surface deformation, pore pressure and, in some cases, lateral deformation within the foundation. There are far too few cases with measured vertical movement within the foundation and our profession suffers in particular from a lack of cases with measured total stress in the foundation.

I have been impressed, repeatedly, by the help that an engineer can get from good portrayal of field data. Poor data portrayal can hide significant facts.

The study of measured performance impresses one that 'inexplicable' performance can occur, e.g. the wide difference in settlement between the three settlement plates at the Northeast Test Embankment.

\section{Predictive techniques}

A given field case rarely permits a conclusive evaluation of a prediction technique. The reasons for this discouraging fact include the following. It is unusual to find a case where the mechanisms involved have been fully and correctly identified. The predictive technique employed in the case is seldom unique. It is more likely to be one in which considerable judgement has been used by the engineer at various stages of the prediction. The only safety factors measured against a shear failure are unity at failure and greater than unity where no failure occurs.

The Profession has great need for techniques for making type A predictions. It would be desirable if these predictive techniques permitted all the judgement decisions to be made at one stage and clearly identified and discussed. An experienced or lucky engineer can use (more appropriately misuse) an inappropriate theory to make a correct prediction. For example, the use of elastic theory, with a modulus obtained using considerable judgement, correctly predicted the settlement of the Lagunillas Preload even though the foundation was loaded far beyond the elastic range.

Table 3 classifies predictions. Most engineering decisions and actions must be based on type A predictions, and sometimes on type B predictions. However, most evaluations of prediction techniques are based on type $\mathrm{C}$ and type $\mathrm{Cl}$ predictions. The analysis of field performance data can be most useful to identifying mechanisms. One must, however, hold some suspicion of using type $\mathrm{Cl}$ predictions to prove the validity of any prediction technique.

Laboratory models and theoretical models offer considerable potential in evaluating prediction techniques. In a model, the engineer can determine with certainty the actual situation and can usually identify the mechanisms operating. Further, he can control or avoid environmental and construction factors which usually complicate field situations. The engineer must, however, remember that his evaluation may prove or disprove his prediction technique for his model. He still faces the very large step from the model to the field situation. 
The practising engineer must recognize that the method and data components of a prediction technique are usually closedly interrelated. In fact, many of the prediction techniques used in practice are semi-empirical. Obviously the user of a semi-empirical technique must follow the entire technique. He should not alter one part of the technique, thinking he has improved it, without carefully checking its empirical basis.

\section{Soil parameters}

The laboratory has played an essential role in the development of soil mechanics. In fact, many of the basic concepts in soil mechanics trace their origins to experiments conducted in a few laboratories during the period from the mid-1940s to 1960 . The laboratory will continue to be important to the practice of soil engineering. Tests to identify mechanisms and tests to study the effects of stress, time and strain on soil behaviour and so on, will be influential in the years ahead.

The soil engineer should not expect that in general he might use laboratory tests alone to measure soil parameters for making correct performance predictions. In situ tests will be used increasingly. These in situ test techniques (e.g. field vane, cone) have inherent advantages over laboratory tests. Some of these advantages are as follows. The engineer is able to obtain a measure of parameters almost continuously with depth and thereby better determine the actual field situation. By obtaining so much soil data, especially as a function of location in the subsoil, the engineer has better possibilities of using probability and decision theory. In situ tests may be less affected by soil disturbance than are laboratory tests. In situ tests may require less time and money than laboratory tests.

There will probably be more use made of test programmes involving both laboratory and in situ tests.

\section{CONCLUSIONS}

Most of my professional life has been focused at the research-engineering interface, i.e. doing research on real civil engineering projects. Preparation for this Rankine Lecture consisted of re-studying field projects in which my MIT associates and I had participated. The eight projects described in this Lecture illustrate and furnish part of the basis for my beliefs.

\section{Importance of predictions}

Predictions-forecasts of events to come-are essential to civil engineering, especially geotechnical engineering. Styles of practice, such as the Observational Method and the Integrated Civil Engineering Project, rest on predicting the performance of civil engincering facilities.

\section{Anatomy of predictions}

In making a soil engineering prediction the engineer goes through the procedure shown in Fig. 2 .

Until the actual field situation and the mechanisms involved have been determined, one cannot usually select appropriate methods of prediction and parameters to be used with these methods. In most prediction techniques the method and parameter components are intimately interrelated. In fact, many of the prediction techniques are semi-empirical, the method and parameter components being uniquely linked together. 
Measured performance

Measuring and portraying clearly the performance of constructed facilities can constitute a significant contribution. The various aspects of performance must be measured in sufficient detail to indicate clearly what mechanisms operated, e.g. the stresses and strains measured as a function of time.

\section{Evaluations of predictions}

The evaluation of a prediction can be extremely important for both the welfare of the project at hand and the improvement of knowledge. The engineer needs to evaluate predictions critical to the project at hand in order to make any necessary changes in the design and/or construction procedures. An examination and intepretation of predictions in the light of the known outcomes of the predicted events can add considerably to our knowledge.

Unfortunately a given field case rarely permits a conclusive evaluation of any prediction technique because it is unusual to find a case where the field situation and the mechanisms involved have been fully identified; the prediction technique employed is seldom a unique one, and is more likely to be one in which considerable judgement has been used by the engineer at various stages of the prediction; and only two figures for factor of safety can be measured, these being unity for failure, and greater than unity for situations that do not fail.

\section{Needed developments}

My professional experience and especially the preparation for this Rankine Lecture leave me highly impressed with, and in fact proud of, the geotechnical profession. We have many powerful tools for solving difficult problems. Even so, I have become increasingly aware of our limitations. There are many situations where we cannot predict the performance of facilities with known reliability. We need to continue our experimental and theoretical work to improve our understanding of mechanisms and to generate simple prediction techniques for the practising engineer.

I am convinced, however, that maximum progress during the 1970 s will come from studies centred in the field, supported by theoretical and laboratory work. I place the highest priority on the development of devices and techniques for determining fundamental soil parameters (lateral stress, pore pressure, shear strength and stress-strain modulus), in situ and, essentially, continuously with depth. Developments of this type will contribute to our ability to determine the actual field situation of a given case, help identify the mechanisms involved and supply soil parameters to be used in the predictions of performance.

\section{ACKNOWLEDGEMENTS}

Many of my present and former MIT colleagues and students worked on the projects described in this Lecture. They gathered field data, ran laboratory tests, made predictions and so on. L. A. Wolfskill participated in most of the cases.

My beliefs have been significantly influenced by discussions with associates. Especially helpful were reviews of drafts of the Lecture by L. A. Wolfskill, C. C. Ladd, T. L. Neff, D. J. D'Appolonia, L. G. Bromwell, H. H. Einstein and W. A. Marr. K. Recker and N. James helped with figures and typing. 
Appreciation goes to the Creole Petroleum Corporation for its high engineering standards and in-depth investigations to meet these standards. Four of the cases described are Creole projects.

Acknowledgement is due to the Massachusetts Department of Public Works and the Bureau of Public Roads, US Department of Transportation, who supported the two I-95 projects.

\section{REFERENCES}

Bjerrum, L. (1972). Embankments on soft ground. Proc. Am. Soc. Civ. Engrs Conf. Performance of Earth and Earth-Supported Structures 11, 1.

Clarke, G. (1971). Putting the prophets in their place. Time Magazine, 15 Feb.

D'Appolonia, D. J., Poulos, H. G. \& Ladd, C. C. (1970). Initial settlement of structures on clay. Soils Report No. 262, Department of Civil Engineering, Massachusetts Institute of Technology.

D'Appolonia, D. J. \& Lambe, T. W. (1970). A method for predicting initial settlement. Jnl Soil Mech. Am. Soc. Civ. Engrs 96, SM2, Mar., 523-544.

D'Appolonia, D. J., Lambe, T. W. \& Poulos, H. G. (1971). Evaluation of pore pressures beneath an embankment. Jnl Soil Mech. Am. Soc. Civ. Engrs 97, SM6, June, 881-898.

Davis, E. H. \& Poulos, H. G. (1968). The use of elastic theory for settlement prediction under threedimensional conditions. Géotechnique 18, No. 1, 67-91.

Davis, E. H. \& Poulos, H. G. (1965). The analysis of settlement under three-dimensional conditions. Symposium on soft ground engineering, Brisbane, Australia.

Davis, E. H. \& Poulos, H. G. (1963). Triaxial testing and three-dimensional settlement analysis. Proc. $4 t h$ Australia-New Zealand Conf. Soil Mech., University of Adelaide, 233-303.

Drew, E. B. (1970). Dam outrage. The Atlantic Monthly, April. Engineering News Record (1972). 27 July.

Gibson, R. E., Schiffman, R. L. \& Pu, S. L. (1967). Plane strain and axially symmetrical consolidation of $a$ clay layer of limited thickness. University of Illinois, MATE Report 67-4.

Heim, H. (1952). Aswan! Alfred A. Knopf, New York.

Höeg, K., Andersland, O. B. \& Rolfsen, E. N. (1969). Undrained behaviour of quick clay under load test at Âsrum. Géotechnique 19, No. 1, 101-115.

Lambe, T. W. (1972). The integrated civil engineering project. Jnl Soil Mech. Am. Soc. Civ. Engrs 98, SM6, June, 531-556.

Lambe, T. W. (1969). Reclaimed land in Kawasaki City, Japan. Jnl Soil Mech. Am. Soc. Civ. Engrs. 95, SM5, Sept., 1181-1198.

Lambe, T. W. (1967). Stress path method. Jnl Soil Mech. Am. Soc. Civ. Engrs 93, SM6, Nov., 309-331.

Lambe, T. W. (1962). Pore pressures in a foundation clay. Jnl Soil Mech. Am. Soc. Civ. Engrs 88, 19.

Lambe, T. W., D'Appolonia, D. J., Karlsrud, K., \& Kirby, R. C. (1972). The performance of the foundation under a high embankment. Jnl Boston Soc. Civ. Engrs 59, No. 2, 71-93.

McQuade, W. (1970). Global earth-shapers in complex competition. Fortune.

Massachesetts Institute of Technology (1969). Performance of an embankment on clay, Interstate-95. Department of Civil Engineering. Research Report, R69-67, Massachusetts Institute of Technology.

Parry, R. D. \& McLeod, J. M. (1967). Proc. 5th Australian-New Zealand Conf. Soil Mech., Auckland, New Zealand. Investigation of slip failure in flood levee at Launceston, 294-300.

Pcck, R. B. (1969). Advantages and limitations of the observational method in applied soil mechanics. Géotechnique 19, No. 2, 171-187.

Schiffman, R. L. \& Gibson, R. E. (1964). Consolidation of non-homogeneous clay layers. Jnl Soil Mech. Am. Soc. Civ. Engrs 90, SM5, Sept., 1-30.

Schmertmann, J. H. (1972). Discussion on Proceedings of the Purdue Conference on Performance. American Society of Civil Engineers.

Skempton, H. W. \& Bjerrum, L. (1959). A contribution to the settlement analysis of foundations on clay. Géotechnique 7, No. 4, 168-178.

Skempton, A. W. (1954). The pore pressure coefficients $A$ and $B$. Géotechnique 4, No. 4, 143-147.

Sterling, C. (1972). Superdams. The Atlantic Monthly, June.

Terzaghi, K. (1936). Presidential address and closing address. Proc. Ist Int. Conf. Soil Mech., Harvard University.

Terzaghi, K. \& Peck, R. B. (1969). Soil mechanics in engineering practice, 2nd edn. Wiley, New York.

Turner, D. J. (1971). Dams and ecology. Civil Engineering-ASCE. US News and World Report, 13 April 1970.

Wisely, W. H. (1972). People, ecology and the Aswan High Dam. Civil Engineering-ASCE. Feb.

Wolfskill, L. A. \& Soydemir, C. (1971). Soil instrumentation for the I-95 MIT-MDPW Test Embankment. Jnl Boston Soc. Civ. Engrs Oct. 


\section{VOTE OF THANKS}

Mr Richard Harkness said that it was a great pleasure and privilege to be asked to propose a vote of thanks to Professor Lambc, whom he had known since 1957 when he went to the Massachusetts Institute of Technology to work in the soil mechanics laboratories for a time. Mr Harkness found the experience so fascinatingly interesting that he stayed for seven years. Many of those present would have been fortunate enough on briefer visits to have experienced some of the excitement of the place, and they would know of the extraordinarily kind and generous hospitality which Professor and Mrs Lambe afforded to visitors.

The title of the Lecture might have led some to expect a discourse on applied astrology. If so, Professor Lambe had brought them down to earth. Predictions were, of course, what soil mechanics was all about, but how many had the patience-and the courage-to conduct an extensive post mortem on predictions and design assumptions after the successful completion of the job? Professor Lambe had prepared to do so, even in the design stage, by his careful providing for long-term field instrumentation, and he had now demonstrated how rewarding a reassessment of the basic design philosophy could be.

It gave Mr Harkness great pleasure to propose a very warm vote of thanks to Professor Lambe for his most interesting and important lecture, and to express the appreciation of those present.

The vote of thanks was accorded with acclamation. 